\title{
Load-deflection behavior of thin-walled plates with multiple bolts in shearing
}

\author{
Y.C. He, Y.C. Wang* \\ School of Mechanical, Aerospace and Civil Engineering, University of Manchester, UK
}

\section{A R T I C L E I N F O}

Article history:

Received 9 November 2011

Received in revised form

23 February 2012

Accepted 23 February 2012

Available online 30 March 2012

Keywords:

Bearing capacity

Bearing deformation

Bearing stiffness

Multiple holes

Analytical solution

Plate bearing

\begin{abstract}
A B S T R A C T
This paper presents a numerical and analytical study of the behavior of thin-walled plates connected by multiple bolts under shear. A validated finite element model has been used to perform a comprehensive set of parametric studies to investigate the effects of different design parameters on the connected plate behavior, including initial stiffness, ultimate resistance and maximum deformation at the ultimate resistance. The design parameters include edge and end distances, bolt spacing, number of bolts along and perpendicular to the loading direction and elongation limit of steel. It has been found that the existing methods for calculating the stiffness and ultimate resistance are directly applicable. The main focus of this paper is the maximum plate deformation at the ultimate plate resistance. Based on the parametric study results, it has been found that strain distributions around the bolt holes for different failure modes, as proposed by the authors for plate connected by a single bolt, are still applicable. However, it is necessary to modify the plate dimension ranges within which the different strain distributions apply to recognize the difference in failure modes for plates with different bolt arrangements.
\end{abstract}

\section{Introduction}

Bolted connection is commonly used in cold-formed thinwalled steel structures. However, some aspects of the bearing behavior of bolted connections remain unclear. The current design codes [1] may be used to predict initial stiffness and load carrying capacity; Kim et al. [2-5] conducted a series of tests and FE simulations to investigate the load carrying capacity of both stainless steel and carbon steel; Salih et al. [6,7] performed some numerical simulations to identify the important factors that affect net-section failure in stainless steel bolted connections and the difference in bearing deformations between carbon and stainless steel bolted connections; Rogers and Hancock $[8,9]$ conducted a series of thin-walled steel connection tests to develop a method to calculate the failure loads of bolted connections bearing on thin-walled G550 and G300 steel sheets; Rex and Easterling [10] focused on predicting the initial stiffness for a single bolted plate under bearing; Yan and Young [11,12] conducted a large series of tests using single-bolted shear connection under constant and changing temperatures to assess the applicability of the current cold-formed steel design rules on connection strength to high temperature condition.
It can be seen from the above literature review that there has been numerous research studies regarding thin-walled shear connections. However, most of them have focused on the connection stiffness and strength, with limited information on the load-deflection relationship.

During a program of previous research, the authors [13] have developed an analytical method to predict the load-deformation behavior of bolted connection with a single bolt under shear. It has been concluded that the initial stiffness and load carrying capacity of such a connection can be predicted using the formulas provided in Eurocode 3 [1] or Australia/New Zealand standards [14]; the authors' main contribution was to develop a method to calculate the maximum connection displacement at the connection strength. This displacement is based on tensile strain distributions around the bolt hole and compressive strain in front of the bolt according to the connection failure modes. The assumed strain distributions were based on examination of an extensive numerical parametric study.

Realistic connections have more than one bolt and this paper explains how the analytical approach may be extended to more practical cases of multiple holes.

\section{Finite element modeling and validation}

In the authors' previous research, the commercial finite element modeling software ABAQUS was used to simulate the

\footnotetext{
* Corresponding author. Tel.: +441612008968.

E-mail address: yong.wang@manchester.ac.uk (Y.C. Wang).
} 


\begin{tabular}{|llll}
\multicolumn{2}{l}{ Nomenclature } & $F_{t}$ & net-section failure load \\
& & $F_{s}$ & end pull-out failure load \\
$A_{n}$ & net cross-section area & $F_{b}$ & bearing failure load \\
$d$ & bolt-hole diameter & $f_{u}$ & ultimate tensile stress \\
$e_{1}$ & end distance & $p_{1}$ & bolt spacing in the loading direction \\
$e_{2}$ & edge distance & $p_{2}$ & bolt spacing perpendicular to load direction \\
$k$ & initial stiffness & $t$ & plate thickness
\end{tabular}

behavior of single bolt-hole plate under shear and the results of the simulation results agreed very well with the authors' tests and the test results of Kim and Kuwamura [2]. This section presents further evidence of validation of the authors' numerical simulation by comparing against the test results of Kim and Kuwamura [2] for multiple bolt-hole plates.

\subsection{Geometric simplification}

Fig. 1 shows the set-up. As in the authors' previous modeling of single-hole plate tests, the bolts were represented by rigid hollow

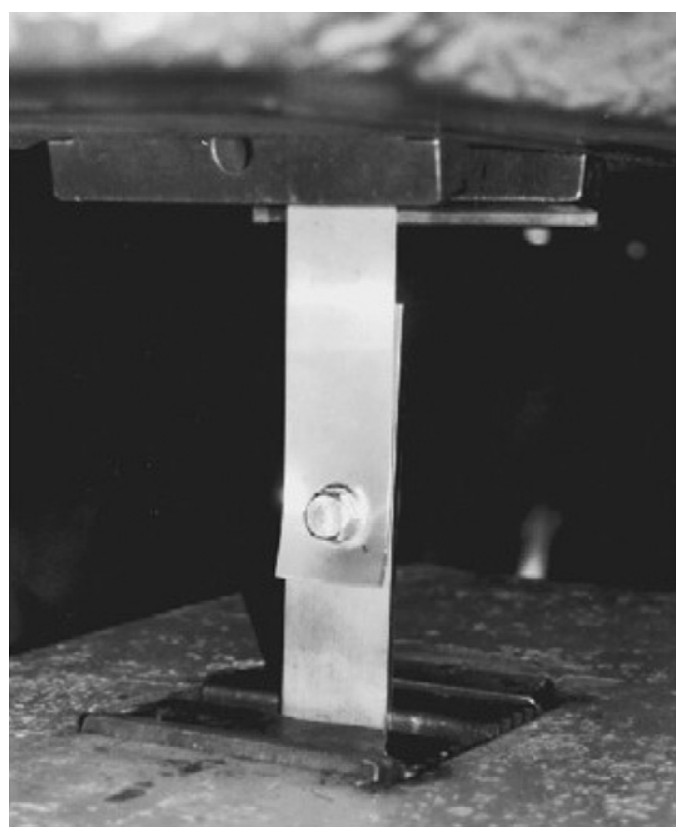

Fig. 1. Kim and Kuwamura [2] test set-up.

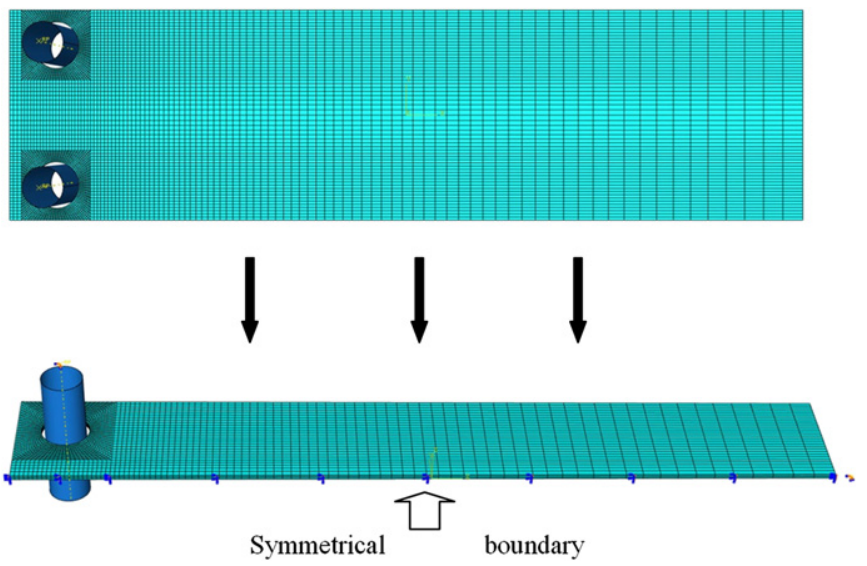

Fig. 2. Half plate for simulation. cylinders during the entire simulation. Due to symmetry, only half of the plate was modeled. Symmetrical boundary conditions (no plate in-plane movement, no rotation about the plate center line), shown in Fig. 2, were applied to the middle line of the test plate.

\subsection{Element type and mesh technique}

ABAQUS element type C3D8R was used to simulate multi-hole plates as for single-hole plates.

Fig. 3 shows 2 different meshes that are applied in the different areas of the plate: a fine mesh around the bolt-hole and a "biased" mesh for the rest of the plate. This "biased" [15] mesh allows the user to define the minimum and maximum element sizes for a part of the structure. The mesh size of the part will change gradually from the minimum to maximum size.

Table 1 shows sensitivity of the simulation results to mesh size for one of the authors' single-hole test and one test of Kim and Kuwamura [2]. A mesh size of $1 / 4$ of the plate thickness is sufficient. This is used in the fine mesh. In the biased mesh, the maximum mesh size is 6 times the fine mesh size.

Table 2 and Fig. 4 compare the authors' simulation results with the test results of Kim and Kuwamura [2] for the multi-hole plate tests. These comparisons further confirm that the authors' simulation model is acceptable.

\section{Parametric study}

The validated ABAQUS model has been used to conduct an extensive series of numerical parametric studies to generate a database of load-deformation behavior for multiple-hole plates with different design parameters for the development of an analytical method. These parameters include the number of bolts in both directions, bolt spacing, end and edge distances, bolt diameter, plate thickness and ultimate strain of steel. Table 3 lists

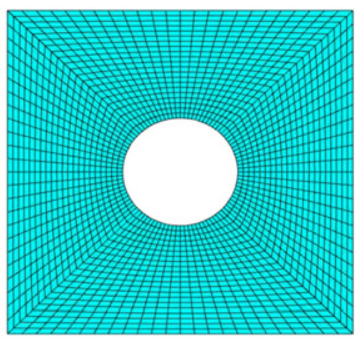

Fine mesh

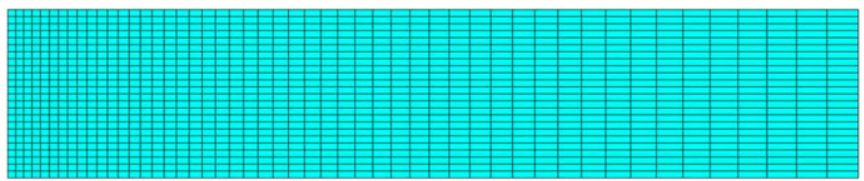

Biased mesh

Fig. 3. Different mesh sizes 
Table 1

Mesh sensitivity for single-hole plates.

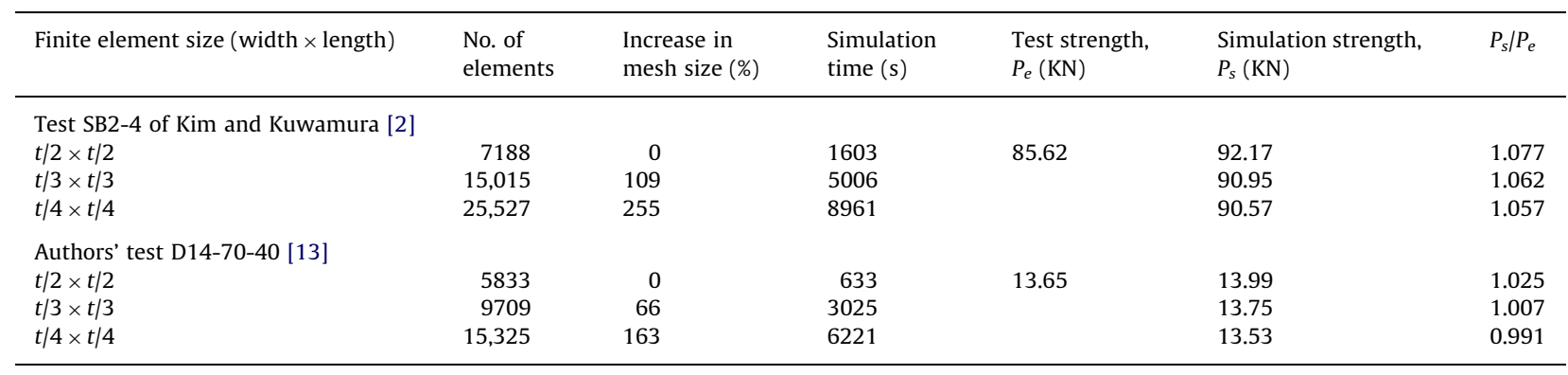

Table 2

Comparison between simulation results and test results from Kim and Kuwamura [2].

\begin{tabular}{|c|c|c|c|c|c|c|c|c|c|c|}
\hline Specimen & $\begin{array}{l}\text { Thickness } \\
(\mathrm{mm})\end{array}$ & $\begin{array}{l}\text { End distance } \\
(\mathrm{mm})\end{array}$ & $\begin{array}{l}\text { Number of } \\
\text { bolts }\end{array}$ & $\begin{array}{l}\text { Test failure } \\
\text { mode }\end{array}$ & $\begin{array}{l}\text { Simulation } \\
\text { failure mode }\end{array}$ & $P_{u e}(\mathrm{KN})$ & $P_{u a 1}(\mathrm{KN})$ & $P_{u a 2}(\mathrm{KN})$ & $P_{u a 1} / P_{u e}$ & $P_{\text {ua } 2} / P_{\text {ue }}$ \\
\hline SB1-4 & 1.46 & 60 & $\begin{array}{l}2 \text { (in direction } \\
\text { of loading) }\end{array}$ & N (Fig. 4a) & N (Fig. 4a) & 43.34 & 43.32 & 41.65 & 1.00 & 0.96 \\
\hline SB2-4 & 2.90 & 60 & 2 (as above) & N (Fig. 4a) & $\mathrm{N}$ (Fig. 4a) & 85.62 & 86.81 & 90.57 & 1.01 & 1.06 \\
\hline $\mathrm{SC} 2-3$ & 2.90 & 30 & $4(2 \times 2)$ & B (Fig. 4b) & B (Fig. 4b) & 161.59 & 173.92 & 176.8 & 1.08 & 1.09 \\
\hline SC2-4 & 2.90 & 60 & $4(2 \times 2)$ & B (Fig. 4b) & B (Fig. 4b) & 162.32 & 152.79 & 159.7 & 0.94 & 0.98 \\
\hline
\end{tabular}

Note: $P_{u e}$ : maximum failure load from test.

$P_{u a 1}$ : Maximum simulated failure load from Kim and Kuwamura [2].

$P_{u a 2}$ : maximum simulated failure load from this study.

Failure mode: $\mathrm{N}$ for Net-section failure mode; B for Bearing failure.
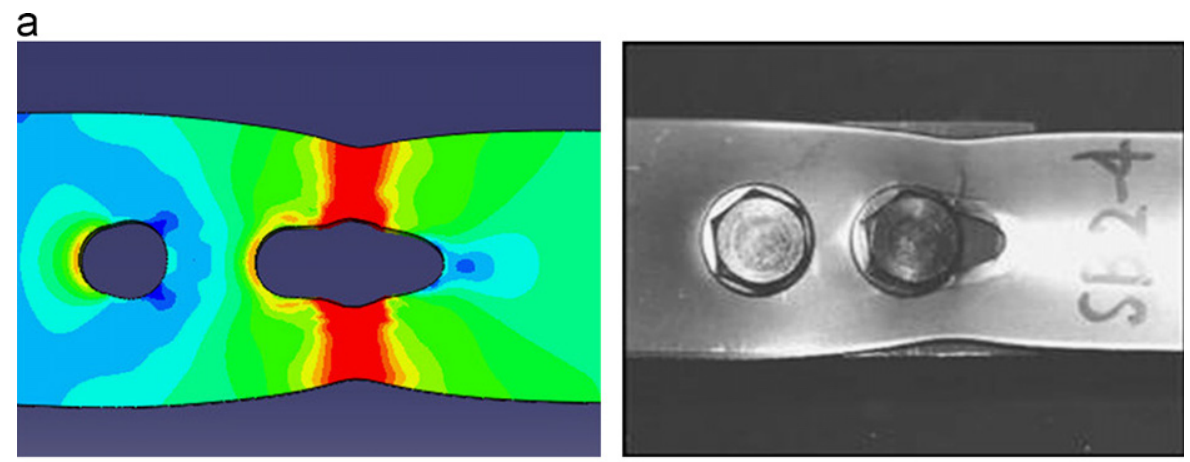

b
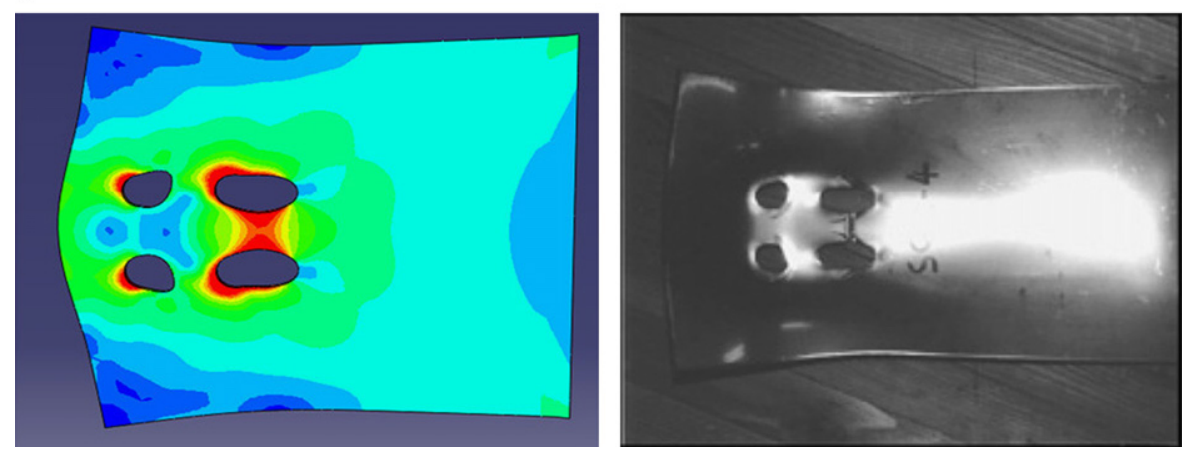

Fig. 4. Comparison of failure modes between FE simulation and Kim's test results. (a) Net section failure, (b) Bearing failure.

the simulation cases. The ranges for end distance $e_{1}$, edge distance $e_{2}$, bolt spacings $p_{1}$ and $p_{2}$ were selected to investigate the changes in failure modes. The ultimate strain 0.35 is from the authors' previous research on plates with single bolt [13]; the strain value of 0.25 is used to ensure that the method derived in this research is applicable to different ultimate strain values. In total 88 simulations were performed.

When simulating a plate with large end and edge distances, local buckling (curling) of the plate may happen at the hole position. In order to eliminate this effect and also to prevent plate 
Table 3

List of assessed parameters.

\begin{tabular}{|c|c|c|c|c|c|c|c|c|}
\hline $\begin{array}{l}\text { Bolt size } \\
(\mathrm{mm})\end{array}$ & $\begin{array}{l}\text { Bolt hole size, } \\
d(\mathrm{~mm})\end{array}$ & $\begin{array}{l}\text { Bolt } \\
\text { number }\end{array}$ & $\begin{array}{l}\text { End } \\
\text { distance, } e_{1}\end{array}$ & $\begin{array}{l}\text { Edge } \\
\text { distance, } e_{2}\end{array}$ & $\begin{array}{l}\text { Spacing } p_{1} \text { (in the } \\
\text { loading direction) }\end{array}$ & $\begin{array}{l}\text { Spacing } p_{2} \text { (across the } \\
\text { loading direction) }\end{array}$ & $\begin{array}{l}\text { Thickness, } t \\
(\mathrm{~mm})\end{array}$ & $\begin{array}{l}\text { Ultimate strain } \\
\text { of steel }\end{array}$ \\
\hline \multirow[t]{5}{*}{12} & \multirow[t]{5}{*}{14} & \multirow[t]{5}{*}{$2 \times 1$} & $1 d$ & $1 d, 1.5 d, 2 d, 2.5 d$ & $3 d$ & $\mathrm{~N} / \mathrm{A}$ & $1.5,3$ & 0.35 \\
\hline & & & $1.5 d$ & $1 d, 1.5 d, 2 d, 2.5 d$ & $3 d$ & $\mathrm{~N} / \mathrm{A}$ & 1.5 & $0.25,0.35$ \\
\hline & & & $2 d$ & $1 d, 1.5 d, 2 d, 2.5 d$ & $3 d$ & $\mathrm{~N} / \mathrm{A}$ & 1.5 & 0.35 \\
\hline & & & $2.5 d$ & $1 d, 1.5 d, 2 d, 2.5 d$ & $3 d$ & $\mathrm{~N} / \mathrm{A}$ & 1.5 & 0.35 \\
\hline & & & $3 d$ & $1 d, 1.5 d, 2 d, 2.5 d$ & $3 d$ & $\mathrm{~N} / \mathrm{A}$ & 1.5 & 0.35 \\
\hline 12 & 14 & $2 \times 1$ & $1 d$ & $1 d, 1.5 d, 2 d, 2.5 d$ & $6 d$ & $\mathrm{~N} / \mathrm{A}$ & 1.5 & 0.35 \\
\hline 12 & 14 & $1 \times 2$ & $1 d$ & $1 d, 1.5 d, 2 d, 2.5 d$ & $\mathrm{~N} / \mathrm{A}$ & $6 d$ & 1.5 & 0.35 \\
\hline 12 & 14 & $3 \times 1$ & $1 d$ & $1 d, 2 d, 3 d, 4 d$ & $6 d$ & $\mathrm{~N} / \mathrm{A}$ & 1.5 & 0.35 \\
\hline 12 & 14 & $3 \times 2$ & $1 d$ & $1 d, 2 d, 3 d, 4 d$ & $6 d$ & $6 d$ & 1.5 & 0.35 \\
\hline \multirow[t]{5}{*}{12} & \multirow[t]{5}{*}{14} & \multirow[t]{5}{*}{$2 \times 1$} & $1 d$ & $1 d, 1.5 d, 2 d, 2.5 d$ & $\mathrm{~N} / \mathrm{A}$ & $3 d$ & 1.5 & 0.35 \\
\hline & & & $1.5 d$ & $1 d, 1.5 d, 2 d, 2.5 d$ & $\mathrm{~N} / \mathrm{A}$ & $3 d$ & 1.5 & 0.35 \\
\hline & & & $2 d$ & $1 d, 1.5 d, 2 d, 2.5 d$ & $\mathrm{~N} / \mathrm{A}$ & $3 d$ & 1.5 & 0.35 \\
\hline & & & $2.5 d$ & $1 d, 1.5 d, 2 d, 2.5 d$ & $\mathrm{~N} / \mathrm{A}$ & $3 d$ & 1.5 & 0.35 \\
\hline & & & $3 d$ & $1 d, 1.5 d, 2 d, 2.5 d$ & $\mathrm{~N} / \mathrm{A}$ & $3 d$ & 1.5 & 0.35 \\
\hline \multirow[t]{4}{*}{12} & \multirow[t]{4}{*}{14} & \multirow[t]{4}{*}{$2 \times 2$} & $1 d$ & $1 d, 2 d, 3 d, 4 d$ & $3 d$ & $3 d$ & 1.5 & 0.35 \\
\hline & & & $1.5 d$ & $1 d, 2 d, 3 d, 4 d$ & $3 d$ & $3 d$ & 1.5 & 0.35 \\
\hline & & & $2 d$ & $1 d, 2 d, 3 d, 4 d$ & $3 d$ & $3 d$ & 1.5 & 0.35 \\
\hline & & & $2.5 d$ & $1 d, 2 d, 3 d, 4 d$ & $3 d$ & $3 d$ & 1.5 & 0.35 \\
\hline 8 & 10 & $2 \times 1$ & $1 d$ & $1 d, 1.5 d, 2 d, 2.5 d$ & $3 d$ & $\mathrm{~N} / \mathrm{A}$ & 1.5 & 0.35 \\
\hline 18 & 20 & $2 \times 1$ & $1 d$ & $1 d, 1.5 d, 2 d, 2.5 d$ & $3 d$ & $\mathrm{~N} / \mathrm{A}$ & 1.5 & 0.35 \\
\hline
\end{tabular}

${ }^{a}$ The first number indicates the number of bolts in the direction of loading and the second number is the number of bolts across the loading direction.

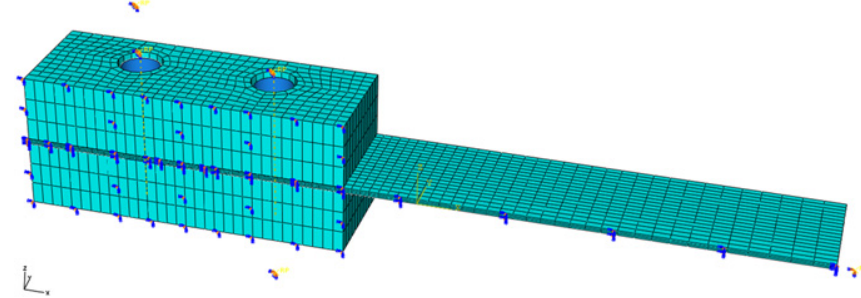

Fig. 5. Simulation model for plate with multiple bolt-holes.

deformation in the thickness direction, one thick plate is placed on each side of the bolted thin plate in the simulation model. These plates are 10 times thicker than the bolted plate and do not deform during the entire simulation. Fig. 5 shows a typical mesh.

\subsection{Development of an analytical model}

As for a single bolt-hole plate, the load-deformation behavior of a multiple bolt-hole plate in shear is assumed to be linear elastic-plastic. As shown in Fig. 6, its load-displacement curve is determined by 3 key parameters: initial stiffness, maximum load and deformation capacity.

\subsubsection{Initial stiffness}

Eurocode 3 [16] provides a stiffness calculation formula for hot-rolled steel plate in bearing with bolts in one single row in the direction of loading

$k=24 n_{b} k_{b} k_{t} d f_{u}$

where $n_{b}$ is the number of bolt row in the loading direction, $k_{b}$ is a factor that considers the effect of end distance and bolt row spacing and $k_{b}=\min \left(k_{b 1}, k_{b 2}+1.25\right)$ with $k_{b 1}=0.25 e_{1} / d+0.5$ and $k_{b 2}=0.25 p_{1} / d+0.375, k_{t}=1.5 t_{j} / d_{M 16}$ is a reduction factor for steel plate thickness, $d_{M 16}$ is the nominal diameter of M16 bolt.

For plate with $m \times n$ bolt-holes in both directions (Fig. 7), the initial stiffness can be calculated as shown below

$k=\sum_{i=1}^{m} k_{i}=k_{1}+k_{2}+\cdots+k_{n}=m k_{\text {row }}$

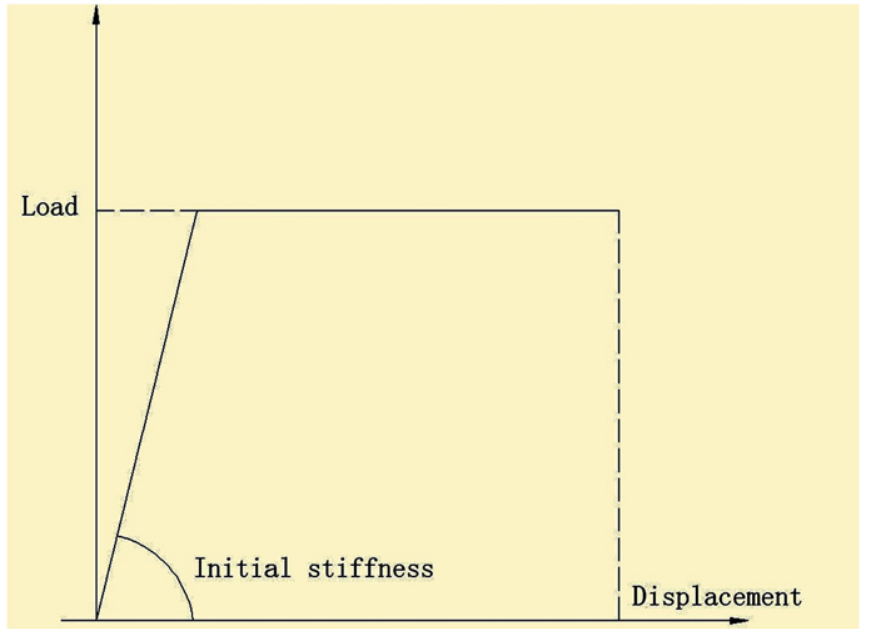

Fig. 6. Assumed analytical load-displacement curve for a multiple bolt-hole plate.

where $k_{\text {row }}$ is the initial stiffness of one row of bolts in the direction of loading, calculated using Eq. (1).

Table 4 compares the FE simulation results with the calculation results using Eq. (2). The average difference between the two sets of results is $13.3 \%$ with a standard deviation of $10.4 \%$. The applicability and extension of the Eurocode 3 formula is confirmed.

To sum up, the Eurocode 3 formula for hot-rolled steel plates in bearing can be directly used for bolted plates in shear with multiple holes in any single direction or in both directions.

\subsubsection{Load-carrying capacity}

For plates with a single bolt, there are 3 possible different failure modes depending on the end and edge distances: netsection fracture, end pull-out failure and bearing failure. For netsection fracture, the following formula can be used to calculate the maximum load:

$F_{t}=A_{n} f_{u}=\left(2 e_{2}-d\right) t f_{u}$ 


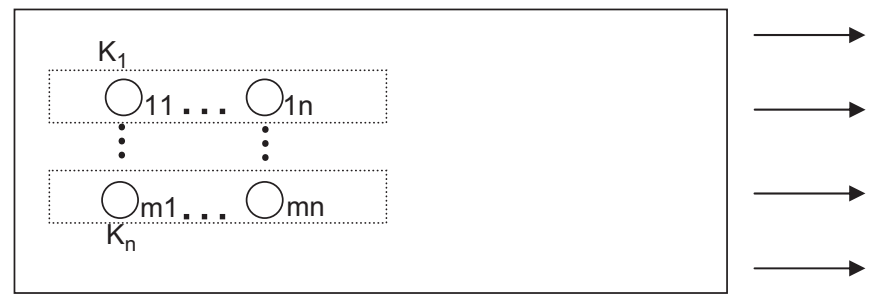

Fig. 7. Plate with multiple bolt-holes in both directions.

Table 4

Comparison of initial stiffness for plates with multiple bolt-holes in both directions.

\begin{tabular}{lllllll}
\hline $\begin{array}{l}\text { End-edge } \\
\text { distance } \\
(\mathrm{mm})\end{array}$ & $\begin{array}{l}\text { Bolt-hole } \\
\text { diameter, } d \\
(\mathrm{~mm})\end{array}$ & $\begin{array}{l}\text { Spacing } P_{1} \\
(\mathrm{~mm})\end{array}$ & $\begin{array}{l}\text { Spacing } P_{2} \\
(\mathrm{~mm})\end{array}$ & $K_{1}$ & $K_{2}$ & $K_{1} / K_{2}$ \\
& & & & & \\
\hline
\end{tabular}

$2 \times 1$ bolt-holes

14-14 14

$14-21 \quad 14$

14-28 14

14-35 14

21-14 14

21-21 14

21-28 14

21-35 14

28-14 14

28-21 14

28-28 14

28-35 14

35-14 14

35-21 14

35-28 14

35-35 14

42-14 14

42-21 14

$\begin{array}{ll}42-28 & 14 \\ 42-35 & 14\end{array}$

$14-14 \quad 14$

14-21 14

14-28 14

14-35 14

$1 \times 2$ bolt-holes

14-14 14

14-21 14

14-28 14

14-35 14

21-14 14

21-21 14

21-28 14

21-35 14

28-14 14

28-21 14

28-28 14

28-35 14

$\begin{array}{ll}35-14 & 14 \\ 35-21 & 14\end{array}$

35-28 14

35-35 14

42-14 14

42-21 14

42-28 $\quad 14$

42-35 14

14-14 14

14-21 14

14-28 14

14-35 14

$1 \times 3$ bolt-holes

14-14 14

14-28 14

14-42 14

14-56 14
Table 4 (continued)

\begin{tabular}{|c|c|c|c|c|c|c|}
\hline $\begin{array}{l}\text { End-edge } \\
\text { distance } \\
(\mathrm{mm})\end{array}$ & $\begin{array}{l}\text { Bolt-hole } \\
\text { diameter, } d \\
(\mathrm{~mm})\end{array}$ & $\begin{array}{l}\text { Vertical } \\
\text { spacing } \\
(\mathrm{mm})\end{array}$ & $\begin{array}{l}\text { Horizontal } \\
\text { spacing } \\
(\mathrm{mm})\end{array}$ & $\begin{array}{l}K_{1}(\mathrm{~N} / \\
\mathrm{MM})\end{array}$ & $\begin{array}{l}K_{2}(\mathrm{~N} / \\
\mathrm{MM})\end{array}$ & $K_{2} / K_{1}$ \\
\hline \multicolumn{7}{|c|}{$2 \times 2$ bolt-holes } \\
\hline $14-14$ & 14 & 42 & 42 & 44,849 & $38,707.2$ & 1.16 \\
\hline $14-21$ & 14 & 42 & 42 & 42,704 & $38,707.2$ & 1.1 \\
\hline $14-28$ & 14 & 42 & 42 & 43,517 & $38,707.2$ & 1.12 \\
\hline $14-35$ & 14 & 42 & 42 & 43,228 & $38,707.2$ & 1.12 \\
\hline $28-14$ & 14 & 42 & 42 & 48,903 & $51,609.6$ & 0.95 \\
\hline $28-21$ & 14 & 42 & 42 & 57,703 & $51,609.6$ & 1.12 \\
\hline $28-28$ & 14 & 42 & 42 & 62,570 & $51,609.6$ & 1.21 \\
\hline $28-35$ & 14 & 42 & 42 & 61,277 & $51,609.6$ & 1.19 \\
\hline \multicolumn{7}{|c|}{$2 \times 3$ bolt-holes } \\
\hline $14-14$ & 14 & 84 & 84 & 56,201 & $58,060.8$ & 0.97 \\
\hline $14-28$ & 14 & 84 & 84 & 63,533 & $58,060.8$ & 1.09 \\
\hline $14-42$ & 14 & 84 & 84 & 64,669 & $58,060.8$ & 1.11 \\
\hline $14-56$ & 14 & 84 & 84 & 65,404 & $58,060.8$ & 1.13 \\
\hline \multicolumn{6}{|c|}{ Average difference } & $13.3 \%$ \\
\hline \multicolumn{6}{|c|}{ Standard deviation } & $10.4 \%$ \\
\hline
\end{tabular}

$K_{1}$ : initial stiffness from ABAQUS simulation.

$K_{2}$ : initial stiffness from Eurocode 3 calculation.

For end pull-out failure, the following formula provided by the Australian/New Zealand [14] and North American design standards [17] can be used to calculate the maximum load:

$F_{s}=t e_{1} f_{u}$

For bearing failure, the following formula provided by Eurocode 3 [16] can be used to predict the maximum load:

$F_{b}=2.5 d t f_{u}$

Net-section fracture happens when $F_{t}<F_{s}$ and $F_{t}<F_{b}$, giving

$e_{2}<\left(e_{1}+d\right) / 2$

$e_{2}<1.75 d$

End pull-out happens when $F_{s}<F_{t}$ and $F_{s}<F_{b}$, leading to

$e_{1} \leq 2 e_{2}-d$

$e_{1} \leq 2.5 d$

Bearing failure happens when $F_{b}<F_{s}$ and $F_{b}<F_{t}$, resulting in

$e_{2} \geq 1.75 d$

$e_{1} \geq 2.5 d$

The failure modes of plates with multiple bolt-holes are similar to plates with single bolt-hole, as explained in the following sections.

For a plate with multiple bolt-holes parallel and perpendicular to the loading direction (Fig. 8), the design strength is the minimum of the following.

The failure load for net-section failure is

$F_{t}=A_{n} f_{u}=(w-m d) t f_{u}$

where $m$ is the number of bolts in the direction perpendicular to loading; $w$ is the plate width.

Except for the outer bolts (bolts 1 to $m$ ), bolt failure is either bearing failure or net-section failure because the bolt spacing in the loading direction is sufficiently large to prevent plate tearing failure between the bolts. The failure mode of the outer bolts is either bearing or end pull-out, depending on the end and edge distances. Net-section failure at the outer bolts will 


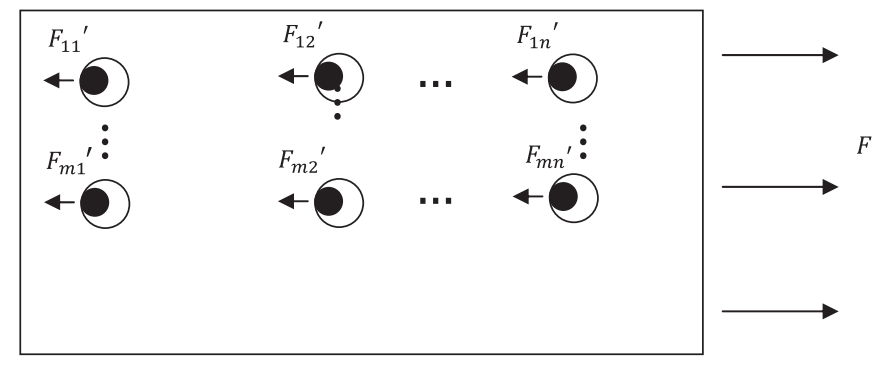

Fig. 8. Load on a plate with multiple bolt-holes in both directions.
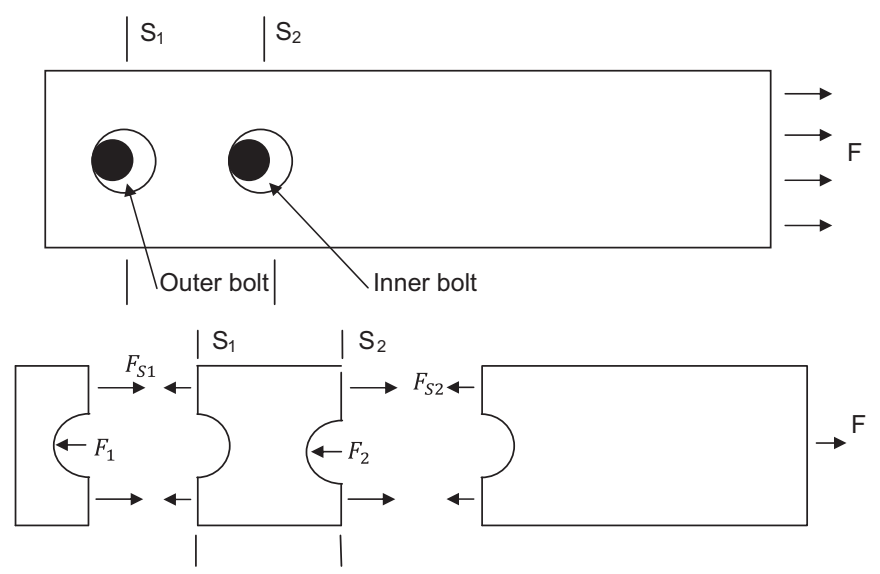

Fig. 9. Loads on plate with two bolt-holes in loading direction.

not happen. This can be demonstrated using two bolts in the direction of loading.

According to Fig. 9

$F=F_{1}+F_{2}$

$F=F_{S 2}$

$F_{1}=F_{S 1}$

Since $F>F_{S 1} \Rightarrow F_{S 2}>F_{S 1}$

Therefore, the force in the cross-section at the inner bolt-hole position is always greater than the force in the cross-section at the outer bolt-hole position, which means that net-section failure will never happen at the outer bolt-hole position.

The bearing resistance of the bolt assembly is

$F_{b}=2.5 m n d t f_{u}$

The end pull-out resistance of the bolt assembly is

$F_{s}=m t e_{1} f_{u}+2.5 m(n-1) d t f_{u}$

Between bearing and end pull-out, bearing failure happens when $e_{1} \geq 2.5 d$ and end pull-out occurs when $e_{1}<2.5 d$.

The conditions for the above three different failure modes are as below.

3.1.2.1. Net-section failure. Net-section failure happens when

$F_{t}=(w-m d) f_{u}<2.5 m n d t f_{u}$ for $e_{1} \geq 2.5 d$

or

$(w-m d) t f_{u}<m(n-1) 2.5 d t f_{u}+m t e_{1} f_{u}$ for $e_{1}<2.5 d$.

Since $w=2 e_{2}+(m-1) p_{2}$, the dimensional conditions are as follows:

For $e_{1}<2.5 d: e_{2}<\left[m e_{1}-(m-1) p_{2}+m(2.5 n-1.5) d\right] / 2$
For $e_{1} \geq 2.5 d: e_{2}<\left[m(2.5 n+1) d-(m-1) p_{2}\right] / 2$

3.1.2.2. Bearing failure $\mathcal{E}$ end pull-out failure. The condition for end pull-out failure is

$e_{1}<2.5 d$ and

$e_{2} \geq\left[m e_{1}-(m-1) p_{2}+m(2.5 n-1.5) d\right] / 2$

The condition for bearing failure is

$e_{1} \geq 2.5 d$ and $e_{2} \geq\left[m(2.5 n+1) d-(m-1) p_{2}\right] / 2$

Table 5 compares the calculated plate load-carrying capacity with FE simulation results and Eurocode 3 calculations. The average difference between FE simulation and proposed calculation results is $6.5 \%$ and the standard deviation is $4.0 \%$, indicating that the calculation results are acceptable. Comparison between Eurocode 3 calculation and FE simulation results gives an average difference of $12.5 \%$ and standard deviation of $9.1 \%$. The Eurocode 3 calculation results are slightly less accurate, but may still be considered acceptable.

\subsubsection{Displacement}

It can be seen from Fig. 10(a) and (b) that the displacement of the plate is the elongation of the first set of inner bolt-holes. Similar to the deformation of a plate with single bolt-hole, the elongation of a plate with multiple bolt-holes can be calculated from the tensile strain distribution around the inner bolt-holes plus any compressive pile up in front of the bolts.

3.1.3.1. Tensile strain distribution. After detailed assessment of strain distributions around the first set of inner bolt holes for the parametric study cases, it was found that the tensile strain distribution in plates with multiple bolt-holes is similar to that with single bolt hole.

In addition to the three pure failure modes (net-section, bearing, end pull-out), the authors' previous research on single bolt-hole plate discovered that it is also necessary to consider the three transitions from one failure mode to another. The same approach will be taken for plates with multiple bolt-holes. As for plates with single bolt hole, the bolt-hole diameter is divided into four equal parts (Fig. 10c) and the strain distribution is assumed to be linear within each segment. It should be noted that the direction of the strain is along the bolt hole to enable calculation of the bolt hole elongation.

Net section failure: For net section failure, it is assumed that the strain at point $C$ is equal to the ultimate tensile strain of steel. The strain at points A, B, D and E is zero. Fig. 11 shows the assumed strain distribution around the bolt hole.

End pull-out failure: It should be noticed that end pull-out happens at the outer bolt-holes. However, the displacement of the plate is calculated as the elongation of the first set of inner boltholes. These two positions coincide when there is only one set of bolts in the loading direction. In this case, the authors' method [13] for plates with single bolt-hole can be directly used. However, when there are more than one set of bolts in the loading direction, it is necessary to consider the interaction between the first set of inner bolts and the outer bolts.

Refer to Fig. 12, the displacement at the 1 st set of inner bolts consists of 2 parts: tensile elongation of the bolt-hole circumference and compressive pilling up in front of the bolt The maximum compressive strain at the bolt/plate contact point is assumed to be 1.0. The compressive strain decreases further away from the bolt and is assumed to be 0 at a distance $1 d$ from the bolt/plate contact, as shown in Fig. 13. Therefore, the maximum compressive displacement is $D_{c}=1 / 2 \varepsilon_{c} d=1 / 2 d$. 
Table 5

Comparison of maximum load between simulation and calculation results for plates with multiple bolt-holes.

\begin{tabular}{|c|c|c|c|c|c|c|c|c|c|}
\hline $\begin{array}{l}\text { End-edge } \\
\text { distance, } e_{1} \\
(\mathrm{~mm})\end{array}$ & $\begin{array}{l}\text { Bolt-hole } \\
\text { diameter, } \\
d(\mathrm{~mm})\end{array}$ & $\begin{array}{l}\text { Spacing } \\
(\mathrm{mm})\end{array}$ & $\begin{array}{l}\text { Bolt } \\
\text { number }\end{array}$ & $\begin{array}{l}\text { Failure } \\
\text { mode }\end{array}$ & $F_{1}(\mathrm{KN})$ & $F_{2}(\mathrm{KN})$ & $F_{3}(\mathrm{KN})$ & $F_{1} / F_{2}$ & $F_{1} / F_{3}$ \\
\hline \multicolumn{10}{|c|}{$4(2 \times 2)$ bolt-holes } \\
\hline $14-14$ & 14 & 42 & 4 & $\mathrm{~N}$ & 22.44 & 20.16 & 20.16 & 1.11 & 1.11 \\
\hline $14-21$ & 14 & 42 & 4 & $\mathrm{~N}$ & 30.84 & 26.88 & 26.88 & 1.15 & 1.15 \\
\hline $14-28$ & 14 & 42 & 4 & $\mathrm{~N}$ & 37.8 & 33.6 & 33.6 & 1.13 & 1.13 \\
\hline $14-35$ & 14 & 42 & 4 & $\mathrm{E}$ & 38.87 & 40.32 & 44.8 & 0.96 & 0.87 \\
\hline $28-14$ & 14 & 42 & 4 & $\mathrm{~N}$ & 22.28 & 20.16 & 20.16 & 1.11 & 1.11 \\
\hline $28-21$ & 14 & 42 & 4 & $\mathrm{~N}$ & 30.55 & 26.88 & 26.88 & 1.14 & 1.14 \\
\hline $28-28$ & 14 & 42 & 4 & $\mathrm{~N}$ & 38.97 & 33.6 & 33.6 & 1.16 & 1.16 \\
\hline $28-35$ & 14 & 42 & 4 & $\mathrm{~N}$ & 44.44 & 40.32 & 40.32 & 1.10 & 1.10 \\
\hline \multicolumn{10}{|c|}{$6(2 \times 3)$ bolt-holes } \\
\hline $14-14$ & 14 & 84 & 6 & $\mathrm{~N}$ & 41.48 & 40.32 & 40.32 & 1.03 & 1.03 \\
\hline $14-28$ & 14 & 84 & 6 & $\mathrm{~N}$ & 58.03 & 60.48 & 51.07 & 0.96 & 1.14 \\
\hline $14-42$ & 14 & 84 & 6 & $\mathrm{~N}$ & 68.84 & 73.92 & 58.5 & 0.93 & 1.18 \\
\hline $14-56$ & 14 & 84 & 6 & B & 79.57 & 80.64 & 78.4 & 0.99 & 1.01 \\
\hline \multicolumn{10}{|c|}{$1 \times 2$ bolt-holes } \\
\hline $14-21$ & 14 & 42 & 2 & $\mathrm{~N}$ & 14.44 & 13.44 & 13.44 & 1.07 & 1.07 \\
\hline $14-28$ & 14 & 42 & 2 & $\mathrm{~N}$ & 20.63 & 20.16 & 20.16 & 1.02 & 1.02 \\
\hline $14-35$ & 14 & 42 & 2 & $\mathrm{E}$ & 20.26 & 23.52 & 22.4 & 0.86 & 0.90 \\
\hline $21-21$ & 14 & 42 & 2 & $\mathrm{~N}$ & 14.25 & 13.44 & 13.44 & 1.06 & 1.06 \\
\hline $21-28$ & 14 & 42 & 2 & $\mathrm{~N}$ & 20.64 & 20.16 & 20.16 & 1.02 & 1.02 \\
\hline $21-35$ & 14 & 42 & 2 & B & 25.49 & 26.88 & 25.2 & 0.95 & 1.01 \\
\hline $28-21$ & 14 & 42 & 2 & $\mathrm{~N}$ & 14.17 & 13.44 & 13.44 & 1.05 & 1.05 \\
\hline $28-28$ & 14 & 42 & 2 & $\mathrm{~N}$ & 20.55 & 20.16 & 20.16 & 1.02 & 1.02 \\
\hline $28-35$ & 14 & 42 & 2 & $\mathrm{~N}$ & 27.63 & 26.88 & 26.88 & 1.03 & 1.03 \\
\hline $35-21$ & 14 & 42 & 2 & $\mathrm{~N}$ & 14.29 & 13.44 & 13.44 & 1.06 & 1.06 \\
\hline $35-28$ & 14 & 42 & 2 & $\mathrm{~N}$ & 21.77 & 20.16 & 20.16 & 1.08 & 1.08 \\
\hline $35-35$ & 14 & 42 & 2 & $\mathrm{~N}$ & 27.86 & 26.88 & 26.88 & 1.04 & 1.04 \\
\hline $42-21$ & 14 & 42 & 2 & $\mathrm{~N}$ & 14.33 & 13.44 & 13.44 & 1.07 & 1.07 \\
\hline $42-28$ & 14 & 42 & 2 & $\mathrm{~N}$ & 21.7 & 20.16 & 20.16 & 1.08 & 1.08 \\
\hline $42-35$ & 14 & 42 & 2 & $\mathrm{~N}$ & 28.6 & 26.88 & 26.88 & 1.06 & 1.06 \\
\hline $14-21$ & 14 & 84 & 2 & $\mathrm{~N}$ & 14.47 & 13.44 & 13.44 & 1.08 & 1.08 \\
\hline $14-28$ & 14 & 84 & 2 & $\mathrm{~N}$ & 20.37 & 20.16 & 18.75 & 1.01 & 1.09 \\
\hline $14-35$ & 14 & 84 & 2 & E & 24.15 & 23.52 & 25.2 & 1.03 & 0.96 \\
\hline \multicolumn{10}{|c|}{$1 \times 3$ bolt-holes } \\
\hline $14-28$ & 14 & 84 & 3 & $\mathrm{~N}$ & 21.71 & 20.16 & 19.16 & 1.08 & 1.13 \\
\hline $14-42$ & 14 & 84 & 3 & $\mathrm{~N}$ & 33 & 33.6 & 29.2 & 0.98 & 1.13 \\
\hline $14-56$ & 14 & 84 & 3 & B & 42.4 & 40.32 & 39.2 & 1.05 & 1.08 \\
\hline \multicolumn{10}{|c|}{$2 \times 1$ bolt-holes } \\
\hline $14-21$ & 14 & 42 & 2 & $\mathrm{E}$ & 13.61 & 13.44 & 11.2 & 1.01 & 1.22 \\
\hline $14-28$ & 14 & 42 & 2 & $E$ & 14.01 & 13.44 & 11.2 & 1.04 & 1.25 \\
\hline $14-35$ & 14 & 42 & 2 & $E$ & 14.11 & 13.44 & 11.2 & 1.05 & 1.26 \\
\hline $21-21$ & 14 & 42 & 2 & $\mathrm{E}$ & 21.55 & 20.16 & 16.8 & 1.07 & 1.28 \\
\hline $21-28$ & 14 & 42 & 2 & $\mathrm{E}$ & 22.1 & 20.16 & 16.8 & 1.10 & 1.32 \\
\hline $21-35$ & 14 & 42 & 2 & $E$ & 22.75 & 20.16 & 16.8 & 1.13 & 1.35 \\
\hline $28-21$ & 14 & 42 & 2 & $\mathrm{E}$ & 27.64 & 26.88 & 22.4 & 1.03 & 1.23 \\
\hline $28-28$ & 14 & 42 & 2 & $E$ & 27.48 & 26.88 & 22.4 & 1.02 & 1.23 \\
\hline $28-35$ & 14 & 42 & 2 & $E$ & 27.68 & 26.88 & 22.4 & 1.03 & 1.24 \\
\hline $35-21$ & 14 & 42 & 2 & B & 28.38 & 28 & 28 & 1.01 & 1.01 \\
\hline $35-28$ & 14 & 42 & 2 & B & 29.86 & 28 & 28 & 1.07 & 1.07 \\
\hline $35-35$ & 14 & 42 & 2 & B & 29.63 & 28 & 28 & 1.06 & 1.06 \\
\hline $42-21$ & 14 & 42 & 2 & B & 28.4 & 33.6 & 33.6 & 0.85 & 0.85 \\
\hline $42-28$ & 14 & 42 & 2 & B & 30.63 & 33.6 & 33.6 & 0.91 & 0.91 \\
\hline $42-35$ & 14 & 42 & 2 & B & 30.92 & 33.6 & 33.6 & 0.92 & 0.92 \\
\hline $14-21$ & 14 & 84 & 2 & $\mathrm{E}$ & 13.97 & 13.44 & 11.2 & 1.04 & 1.25 \\
\hline $14-28$ & 14 & 84 & 2 & $\mathrm{E}$ & 14.4 & 13.44 & 11.2 & 1.07 & 1.29 \\
\hline $14-35$ & 14 & 84 & 2 & $E$ & 14.56 & 13.44 & 11.2 & 1.08 & 1.30 \\
\hline \multirow{2}{*}{\multicolumn{8}{|c|}{$\begin{array}{l}\text { Average difference } \\
\text { Standard deviation }\end{array}$}} & $6.50 \%$ & $12.50 \%$ \\
\hline & & & & & & & & $4.00 \%$ & $9.10 \%$ \\
\hline
\end{tabular}

$F_{1}$ : maximum failure load from ABAQUS simulation.

$F_{2}$ : maximum failure load from proposed calculation.

$F_{3}$ : maximum failure load from Eurocode 3 calculation.

$\mathrm{N}$ : net-section failure.

E: end pull-out failure.

$\mathrm{B}$ : bearing failure.

As can be seen in Fig. 14, the tensile deformation at the 1st set of inner bolts (Bolt 2 in Fig. 14) does not cause any deformation at the outer bolts (Bolt 1) because the distances between the bolts in the loading direction can be maintained without movement of the plate at the outer bolt position. However, when compressive deformation at the 1 st set of inner bolts (Bolt 2 in Fig. 14) occurs, 


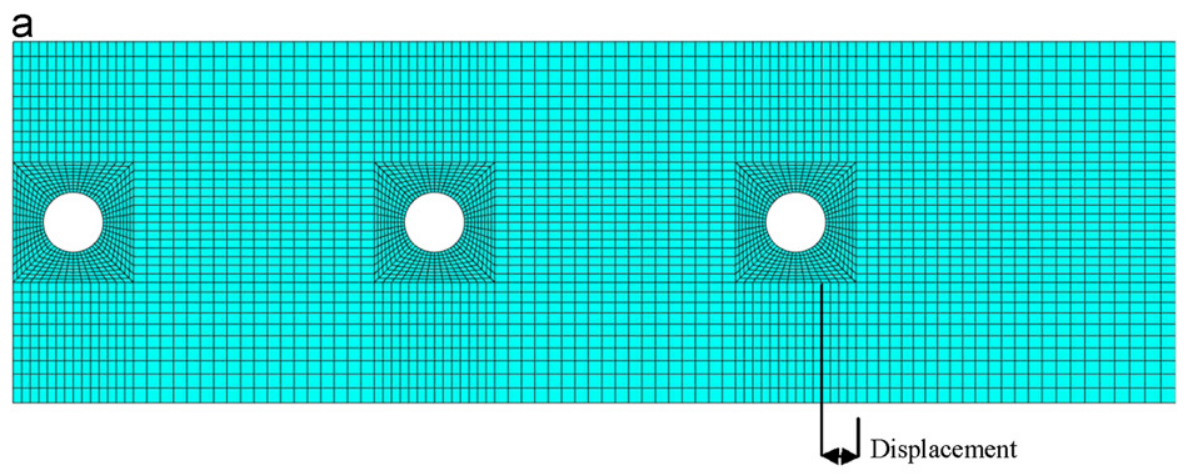

b

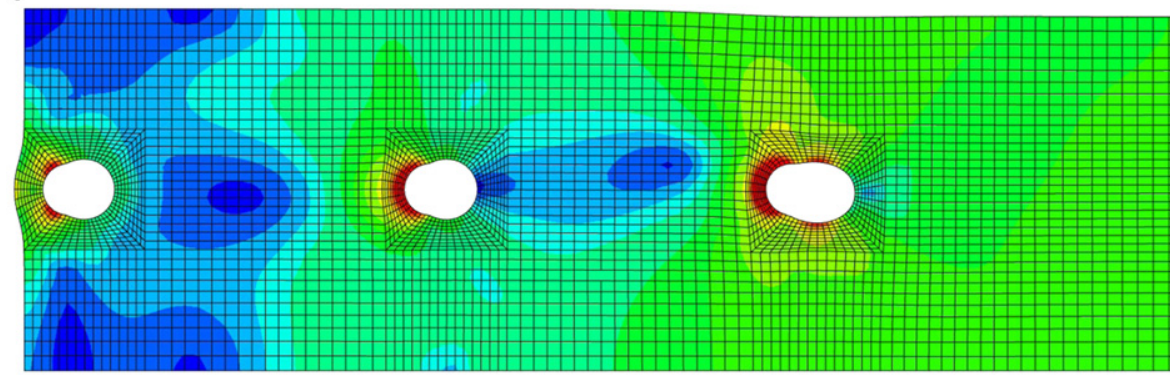

C

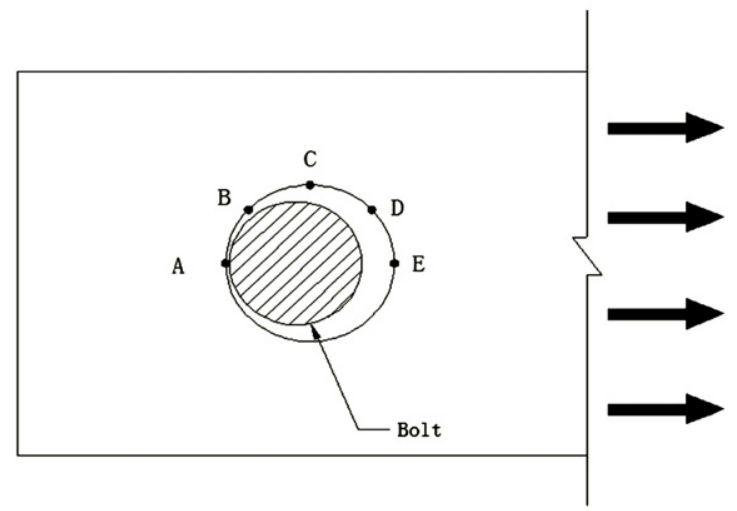

Fig. 10. Displacement of plate with multiple bolt-holes.

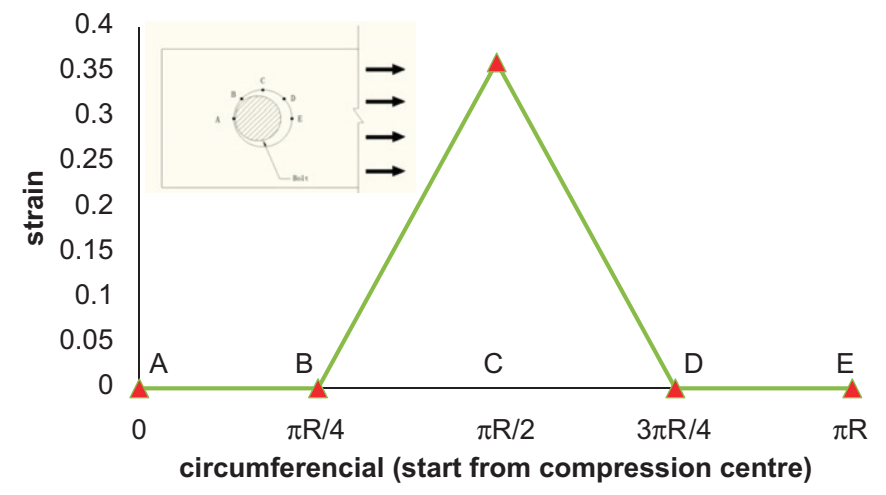

Fig. 11. Assumed tensile strain distribution for net-section failure.

deformations at bolts after the 1 st set of inner bolts have to happen. The required amount of deformation at each hole is different and decreases further away from the 1 st set of inner bolts. In fact, when there are three $(n=3)$ or more $(n>3)$ sets of bolts in the loading direction, the required amount of deformation at the outer bolts is reduced to such a low level that end pull-out will not occur. But if there are two sets of bolts in the loading direction and if the end distance is small $\left(1 d<e_{1}<1.3 d\right)$, it is possible for end pull-out of the outer bolts to happen if the compressive deformation $(1 / 2 d)$ at the 1 st set of inner bolts is greater than the achievable displacement at the outer bolts for end pull-out. The achievable displacement for end pull-out of the other bolts can be calculated as for plates with single bolt hole. This can be calculated by assuming the following strain distributions (refer to Fig. 15): zero strain at positions C, D and E; $\varepsilon_{B}=\varepsilon_{t}+\mu \varepsilon_{r}$, where $\varepsilon_{t}$ is the ultimate tensile strain of steel, $\mu$ is Poisson's ratio $(0.3)$ and $\varepsilon_{r}$ is the radial compressive strain due to bearing. It is assumed that $\varepsilon_{r}=1.0$.

In this case, the achievable displacement for end pull-out of the outer bolts should be added to the tensile elongation of the 1 st set of inner bolt-holes to give the total displacement of the connection assembly.

Bearing failure: When bearing failure happens, it is assumed that the strains at points $C, D$ and $E$ are zero. The strain at point $A$ is $\varepsilon_{B}=\varepsilon_{t}+\mu \varepsilon_{r}$ owing to combined tension and compression in front of the bolt. For example, in Fig. 16, the strain at point $A$ is $0.35+0.3 \times 1.0=0.65$. The strain distribution between $A$ and $C$ is linear so the strain at point B is half of that at point A. Fig. 16 shows the complete assumed tensile strain distribution around the bolt hole under bearing failure.

Mixed failure modes: Based on the above discussions for end pull-out failure of the outer bolts, it is necessary to separate the 

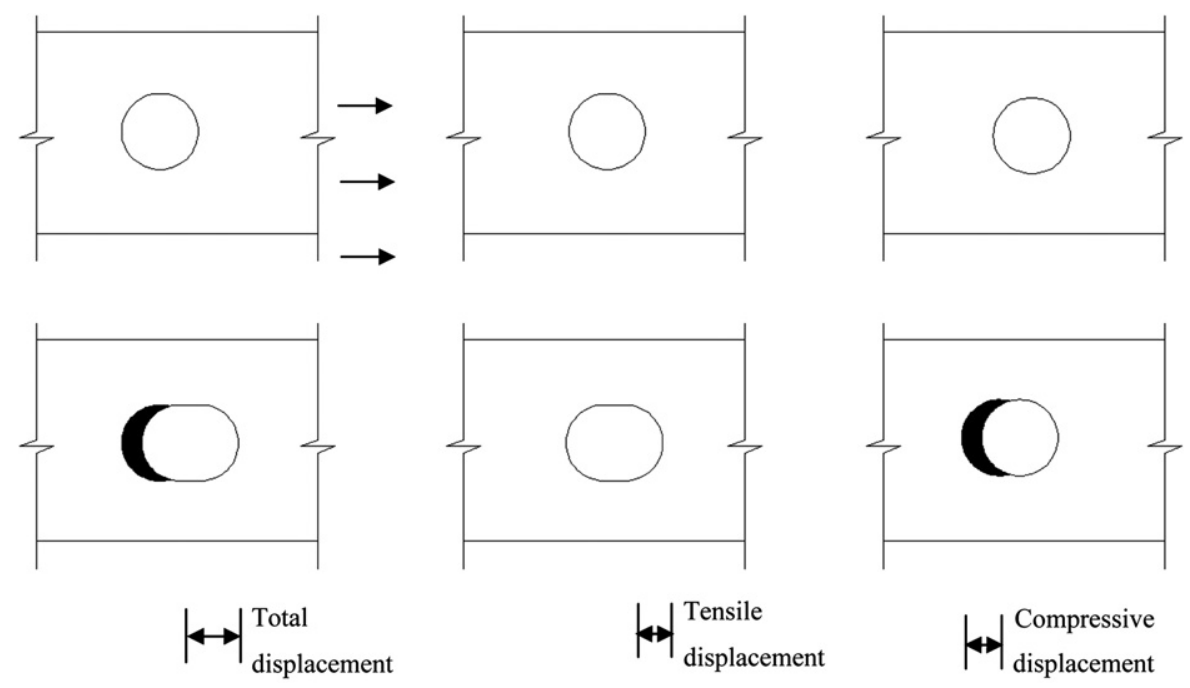

Fig. 12. Two components of total displacement.

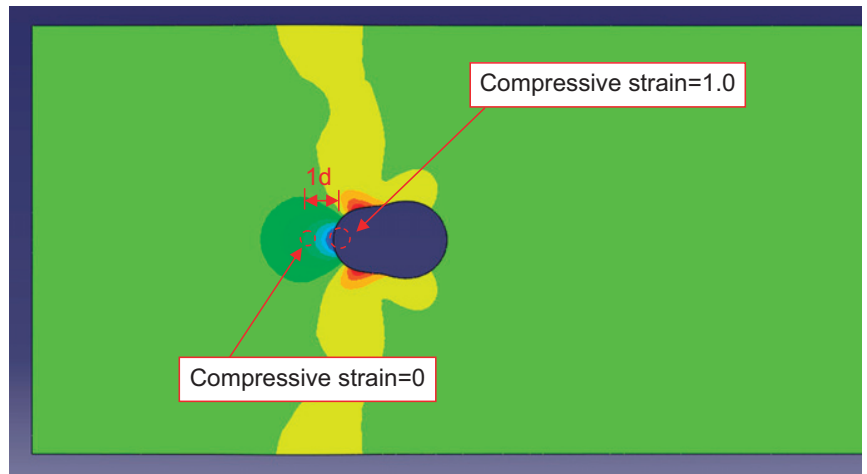

Fig. 13. Example of compressive strain distribution along plate length.
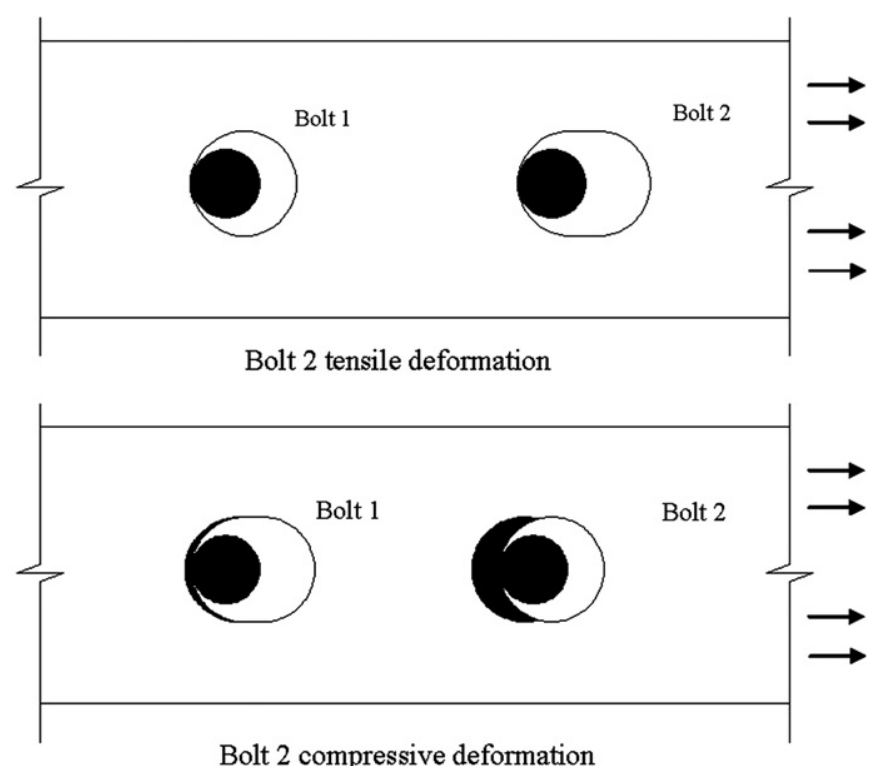

Fig. 14. Relationship between displacements at different bolt-holes.

considerations into one set of bolts in the loading direction $(n=1)$, two sets of bolts in the loading direction $(n=2)$ and three or more sets of bolts in the loading direction $(n \geq 3)$. For $n=1$, the authors' previous method (reference) on plates with single bolt can be used. This will not be repeated here.

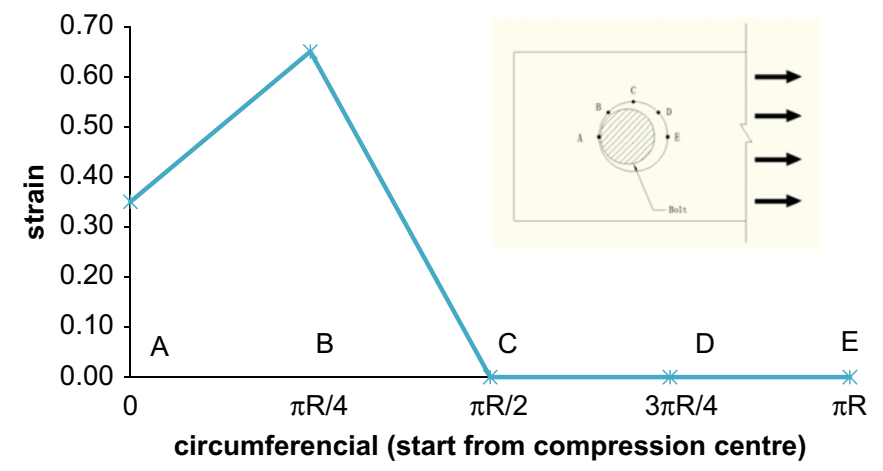

Fig. 15. Assumed tensile strain distribution for end pull-out failure at the outer bolts.

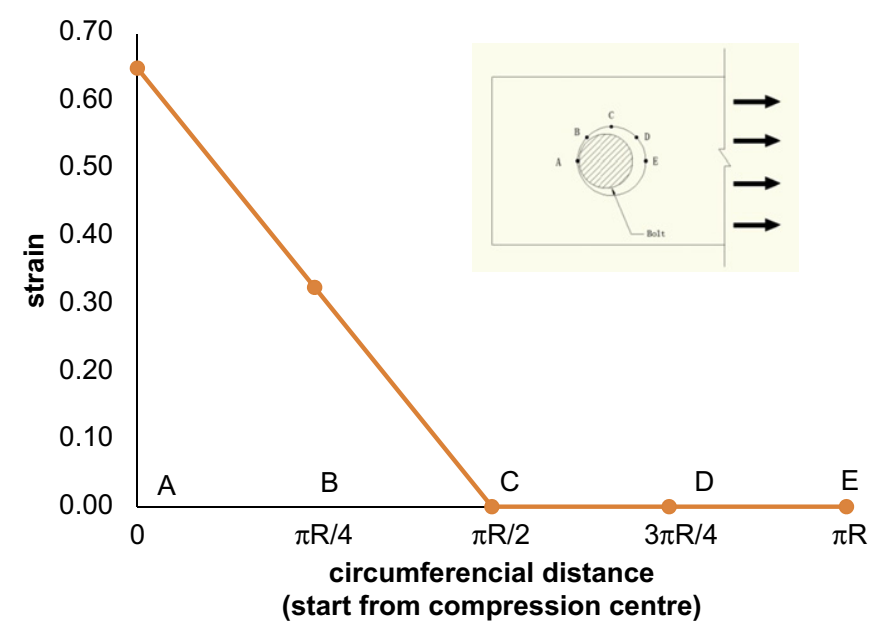

Fig. 16. Assumed tensile strain distribution for bearing failure.

3.1.3.2. Plate with more than 2 bolt-holes in loading direction $(n \geq 3)$. In this case, there is only one mixed failure mode: netsection/bearing mixed failure. From Eqs. (13) and (15), it can be seen that when $e_{1}<2.5 d$, edge distance $e_{2}=\left[m e_{1}-(m-1) p_{2}+m\right.$ $(2.5 n-1.5) d] / 2$ marks the separation between net-section failure and bearing failure. It is assumed that when $e_{2} \leq 1 d$, then tensile strain around the bolt-hole follows pure net-section failure tensile strain distribution (Fig. 17). When $e_{2} \geq\left[m e_{1}-(m-1) p_{2}+\right.$ $m(2.5 n-1.5) d] / 2$, the tensile strain around the bolt-hole follows 


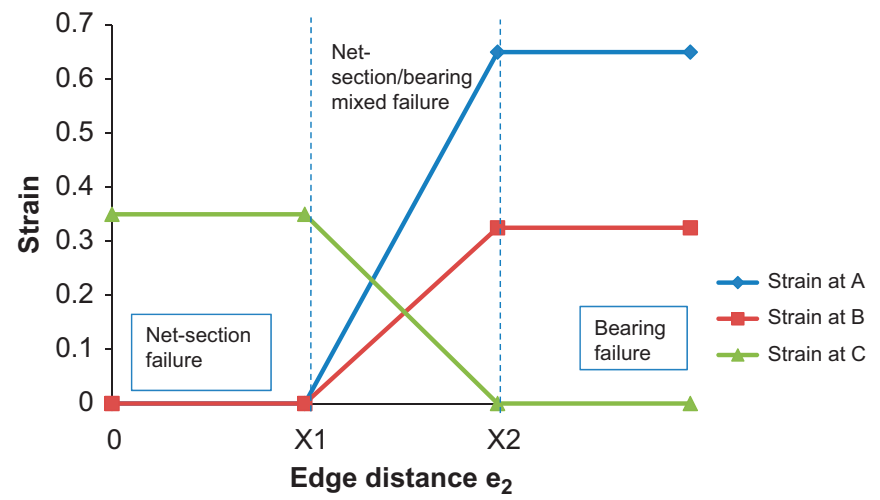

$$
\begin{aligned}
& X_{1}=1 d \\
& \text { When } e_{1}<2.5 d, \\
& X_{2}=\left[m_{1}-(m-1) p_{2}+m(2.5 n-1.5) d\right] / 2,1.75 d \\
& \text { but } e_{2} \geq 1.5 d \\
& \text { When } e_{1} \geq 2.5 d, \\
& X_{2}=\left[m(2.5 n+1) d-(m-1) p_{2}\right] / 2 \\
& \text { but } e_{2} \geq 1.5 d
\end{aligned}
$$

Fig. 17. Assumed strain values for plate with multiple bolt-holes in both horizontal and vertical directions, $n \geq 3$.

bearing failure strain distribution (Fig. 17). When $e_{2}$ is between the range of $1 d$ and $\left[m e_{1}-(m-1) p_{2}+m(2.5 n-1.5) d\right] / 2$, linear interpolation can be applied. Similarly, from Eqs. (14) and (16), it can be seen that when $e_{1} \geq 2.5 d, e_{2}=\left[m(2.5 n+1) d-(m-1) p_{2}\right] / 2$ is the critical point to separate net-section failure from bearing failure. It is assumed that when $e_{2} \leq 1 d$, the tensile strain around the bolt-hole follows net-section strain distribution (Fig. 17). When $e_{2} \geq[\mathrm{m}$ $\left.(2.5 n+1) d-(m-1) p_{2}\right] / 2$, the tensile strain around the bolt-hole follows bearing failure strain distribution. When $e_{2}$ is between $1 d$ and $\left[m(2.5 n+1) d-(m-1) p_{2}\right] / 2$, linear interpolation is applied.

Fig. 17 shows the transition in tensile strain distribution at different critical points with increasing $e_{2}$. In some cases, it is possible that the value $\left[m e_{1}-(m-1) p_{2}+m(2.5 n-1.5) d\right] / 2$ (for $\left.e_{1}<2.5 d\right)$ or $\left[m(2.5 n+1) d-(m-1) p_{2}\right] / 2$ (for $\left.e_{1} \geq 2.5 d\right)$ is negative or smaller than $1 d$. This means that bearing failure dominates and the tensile strain around the bolt-hole should follow bearing failure strain distribution.

3.1.3.3. Plate with 2 bolt-holes in loading direction. In this case, the bearing failure and end pull-out failure should be linked. Therefore, for plates with 2 bolt-holes in the loading direction, the only mixed failure mode is mixed net-section and bearing/end pull-out failure.

Putting $n=2$ into Eqs. (13) and (14) gives

For $e_{1}<2.5 d, e_{2}<\left[3.5 m d+m e_{1}-(m-1) p_{2}\right] / 2$

For $e_{1} \geq 2.5 d, e_{2}<\left[6 m d-(m-1) p_{2}\right] / 2$

This means that for the end distance $e_{1}<2.5 d$, the edge distance $e_{2}=\left[3.5 m d+m e_{1}-(m-1) p_{2}\right] / 2$ marks the separation of net-section and bearing/end pull-out failure; for the end distance $e_{1} \geq 2.5 d$, the edge distance $e_{2}=\left[6 m d-(m-1) p_{2}\right] / 2$ marks the separation of netsection and bearing failure. It is assumed that when $e_{2} \leq 1 d$, the strain distribution is according to net-section failure. When $e_{2} \geq$ $\left[3.5 m d+m e_{1}-(m-1) p_{2}\right] / 2$ (for $\left.e_{1}<2.5 d\right)$ or $e_{2} \geq\left[6 m d-(m-1) p_{2}\right] /$ 2 (for $e_{1} \geq 2.5 d$ ), the strain distribution is according to bearing/end pull-out failure. During the transition period, linear interpolation can be used. Fig. 18 shows the assumed change of strain values depending on the edge distance $e_{2}$.

3.1.3.4. Compressive strain. In order to calculate the bolt hole elongation due to compressive pile-up, it is assumed that that

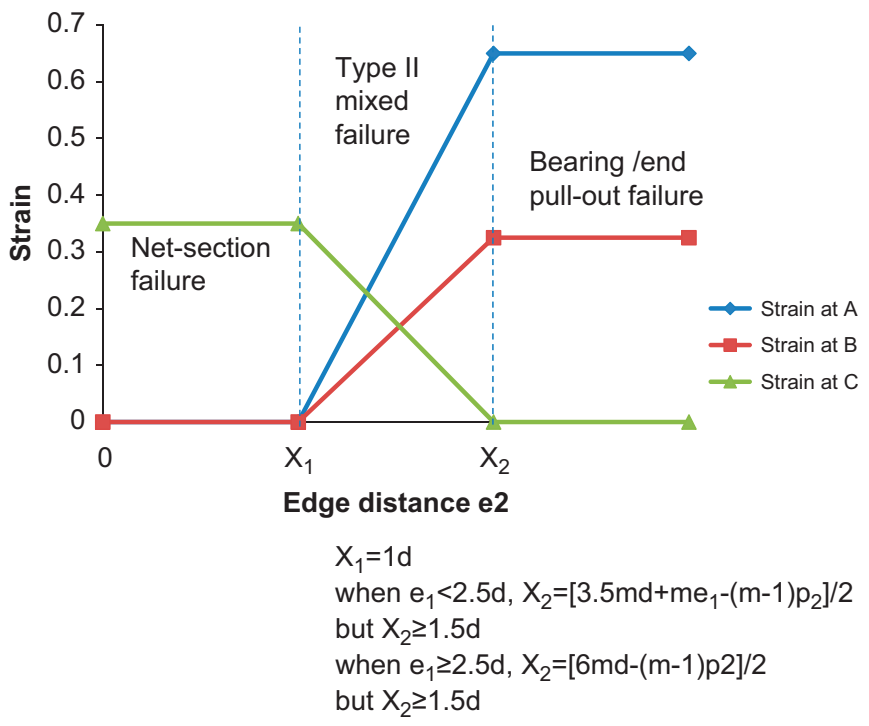

Fig. 18. Assumed strain values at different critical points for transition from netsection to bearing/end pull-out failure.

the compressive strain changes from the maximum value at the bolt/plate contact point to zero at a distance of one bolt diameter away (or the actual edge of the plate if less), as shown in Fig. 13.

The same plate geometry conditions used to determine the different plate pure and mixed failure modes for tensile strain distributions should be used to determine the compressive strain distributions.

For plates with only one bolt in the loading direction, the authors' method for plates with single-bolt [13] can be used. If there are two bolt holes in the loading direction and end pull-out happens, the compressive displacement of the 1st set of inner bolts should be replaced by the end pull-out displacement of the outer bolts if the latter is smaller. The compressive displacement of the 1 st set of inner bolts can be calculated following the same procedure below for plates with 3 or more bolts in the loading direction.

For plates with 3 or more bolts in the loading direction, end pull-out failure will not happen. If pure bearing failure occurs, the maximum compressive strain is assumed to be 1.0 as in the authors' previous study for plates with a single bolt. The compressive strain reaches maximum value when $e_{2} \geq \min \left\{\left[m e_{1}-(m-1) p_{2}+m\right.\right.$ $(2.5 n-1.5) d] / 2,1.75 d\}$ according to Eq. (15). When $e_{2} \leq 0.75 d$ (based on the authors' research for plates with a single bolt for consistency), the compressive strain is equal to zero. When the edge distance falls between these two values, linear interpolation can be used.

As mentioned before, it is possible that the value of $e_{2}=$ $\left[m e_{1}-(m-1) p_{2}+m(2.5 n-1.5) d\right] / 2$ is negative or smaller than $1 d$. This means that plate bearing failure controls and the compressive strain should be assumed to reach the maximum value 1.0.

Table 6 and Fig. 19 compare plate displacements between the FE simulated results and the calculated results. It can be seen that the simulated and calculated plate displacements agree well, with an average difference of $14.3 \%$ and $9.4 \%$ standard deviation.

\section{Summary of displacement calculation procedure}

To sum up, the procedure for calculating the connection elongation at the maximum load is as follows:

\subsection{Tensile strain}

1. Determine the failure mode of the connection by comparing the end distance, edge distance, bolt-hole diameter and spacing. 
Table 6

Displacement comparison between ABAQUS simulations and calculation results.

\begin{tabular}{|c|c|c|c|c|c|c|}
\hline $\begin{array}{l}\text { End-edge } \\
\text { distance } \\
(\mathrm{mm})\end{array}$ & $\begin{array}{l}\text { Bolt-hole } \\
\text { diameter, } d \\
(\mathrm{~mm})\end{array}$ & $\begin{array}{l}P_{1} \\
(\mathrm{~mm})\end{array}$ & $\begin{array}{l}P_{2} \\
(\mathrm{~mm})\end{array}$ & $D_{1}$ & $D_{2}$ & $D_{2} / D_{1}$ \\
\hline \multicolumn{7}{|c|}{$1 \times 2$ bolt-holes } \\
\hline $14-14$ & 14 & 42 & $\mathrm{~N} / \mathrm{A}$ & 3.53 & 3.11 & 0.88 \\
\hline $14-21$ & 14 & 42 & $\mathrm{~N} / \mathrm{A}$ & 5.85 & 5.50 & 0.94 \\
\hline $14-28$ & 14 & 42 & $\mathrm{~N} / \mathrm{A}$ & 8.84 & 8.86 & 1.00 \\
\hline $14-35$ & 14 & 42 & $\mathrm{~N} / \mathrm{A}$ & 7.32 & 10.58 & 1.15 \\
\hline $21-14$ & 14 & 42 & $\mathrm{~N} / \mathrm{A}$ & 3.37 & 2.90 & 0.86 \\
\hline $21-21$ & 14 & 42 & $\mathrm{~N} / \mathrm{A}$ & 4.75 & 4.85 & 1.02 \\
\hline $21-28$ & 14 & 42 & $\mathrm{~N} / \mathrm{A}$ & 6.52 & 7.72 & 1.18 \\
\hline $21-35$ & 14 & 42 & $\mathrm{~N} / \mathrm{A}$ & 7.85 & 10.58 & 1.05 \\
\hline $28-14$ & 14 & 42 & $\mathrm{~N} / \mathrm{A}$ & 3.40 & 2.84 & 0.83 \\
\hline $28-21$ & 14 & 42 & $\mathrm{~N} / \mathrm{A}$ & 4.37 & 4.36 & 1.00 \\
\hline $28-28$ & 14 & 42 & $\mathrm{~N} / \mathrm{A}$ & 5.73 & 6.89 & 1.20 \\
\hline $28-35$ & 14 & 42 & $\mathrm{~N} / \mathrm{A}$ & 8.38 & 9.38 & 0.86 \\
\hline $35-14$ & 14 & 42 & $\mathrm{~N} / \mathrm{A}$ & 3.10 & 2.71 & 0.87 \\
\hline $35-21$ & 14 & 42 & $\mathrm{~N} / \mathrm{A}$ & 4.66 & 3.20 & 0.69 \\
\hline $35-28$ & 14 & 42 & $\mathrm{~N} / \mathrm{A}$ & 8.45 & 6.20 & 0.73 \\
\hline $35-35$ & 14 & 42 & $\mathrm{~N} / \mathrm{A}$ & 9.34 & 8.36 & 0.89 \\
\hline $42-14$ & 14 & 42 & $\mathrm{~N} / \mathrm{A}$ & 2.94 & 2.71 & 0.92 \\
\hline $42-21$ & 14 & 42 & $\mathrm{~N} / \mathrm{A}$ & 4.74 & 3.20 & 0.68 \\
\hline $42-28$ & 14 & 42 & $\mathrm{~N} / \mathrm{A}$ & 8.00 & 6.20 & 0.77 \\
\hline $42-35$ & 14 & 42 & $\mathrm{~N} / \mathrm{A}$ & 10.83 & 8.36 & 0.77 \\
\hline \multicolumn{7}{|c|}{$2 \times 1$ bolt-holes } \\
\hline $14-14$ & 14 & $\mathrm{~N} / \mathrm{A}$ & 42 & 4.99 & 5.21 & 1.04 \\
\hline $14-21$ & 14 & $\mathrm{~N} / \mathrm{A}$ & 42 & 5.44 & 5.21 & 0.96 \\
\hline $14-28$ & 14 & $\mathrm{~N} / \mathrm{A}$ & 42 & 5.26 & 5.21 & 0.99 \\
\hline $14-35$ & 14 & $\mathrm{~N} / \mathrm{A}$ & 42 & 5.37 & 5.21 & 0.97 \\
\hline $21-14$ & 14 & $\mathrm{~N} / \mathrm{A}$ & 42 & 4.54 & 2.76 & 0.61 \\
\hline $21-21$ & 14 & $\mathrm{~N} / \mathrm{A}$ & 42 & 7.00 & 8.74 & 1.25 \\
\hline $21-28$ & 14 & $\mathrm{~N} / \mathrm{A}$ & 42 & 6.91 & 8.74 & 1.26 \\
\hline $21-35$ & 14 & $\mathrm{~N} / \mathrm{A}$ & 42 & 6.93 & 8.74 & 1.26 \\
\hline $28-14$ & 14 & $\mathrm{~N} / \mathrm{A}$ & 42 & 4.32 & 4.24 & 0.98 \\
\hline $28-21$ & 14 & $\mathrm{~N} / \mathrm{A}$ & 42 & 11.81 & 11.53 & 0.98 \\
\hline $28-28$ & 14 & $\mathrm{~N} / \mathrm{A}$ & 42 & 10.43 & 11.53 & 1.11 \\
\hline $28-35$ & 14 & $\mathrm{~N} / \mathrm{A}$ & 42 & 9.91 & 11.53 & 1.16 \\
\hline $35-14$ & 14 & $\mathrm{~N} / \mathrm{A}$ & 42 & 5.16 & 4.24 & 0.82 \\
\hline $35-21$ & 14 & $\mathrm{~N} / \mathrm{A}$ & 42 & 7.51 & 8.29 & 1.10 \\
\hline $35-28$ & 14 & $\mathrm{~N} / \mathrm{A}$ & 42 & 9.20 & 10.58 & 1.15 \\
\hline $35-35$ & 14 & $\mathrm{~N} / \mathrm{A}$ & 42 & 8.70 & 10.58 & 1.22 \\
\hline $42-14$ & 14 & $\mathrm{~N} / \mathrm{A}$ & 42 & 5.00 & 4.24 & 0.85 \\
\hline $42-21$ & 14 & $\mathrm{~N} / \mathrm{A}$ & 42 & 7.50 & 8.29 & 1.11 \\
\hline $42-28$ & 14 & $\mathrm{~N} / \mathrm{A}$ & 42 & 8.56 & 10.58 & 1.24 \\
\hline $42-35$ & 14 & $\mathrm{~N} / \mathrm{A}$ & 42 & 8.47 & 10.58 & 1.25 \\
\hline \multicolumn{7}{|c|}{$2 \times 2$ bolt-holes } \\
\hline $14-14$ & 14 & 42 & 42 & 3.83 & 3.67 & 0.96 \\
\hline $14-21$ & 14 & 42 & 42 & 6.81 & 7.56 & 1.11 \\
\hline $14-28$ & 14 & 42 & 42 & 9.78 & 9.77 & 1.00 \\
\hline $14-35$ & 14 & 42 & 42 & 8.67 & 10.15 & 1.17 \\
\hline $21-14$ & 14 & 42 & 42 & 3.92 & 3.67 & 0.94 \\
\hline $21-21$ & 14 & 42 & 42 & 6.02 & 7.53 & 1.25 \\
\hline $21-28$ & 14 & 42 & 42 & 9.12 & 9.58 & 1.05 \\
\hline $21-35$ & 14 & 42 & 42 & 8.71 & 9.94 & 1.14 \\
\hline $28-14$ & 14 & 42 & 42 & 3.25 & 3.67 & 1.13 \\
\hline $28-21$ & 14 & 42 & 42 & 6.19 & 7.42 & 1.20 \\
\hline $28-28$ & 14 & 42 & 42 & 10.65 & 9.47 & 0.89 \\
\hline $28-35$ & 14 & 42 & 42 & 10.09 & 9.77 & 0.97 \\
\hline $35-14$ & 14 & 42 & 42 & 3.21 & 3.67 & 1.14 \\
\hline $35-21$ & 14 & 42 & 42 & 5.79 & 7.42 & 1.28 \\
\hline $35-28$ & 14 & 42 & 42 & 8.15 & 9.39 & 1.15 \\
\hline $35-35$ & 14 & 42 & 42 & 7.90 & 9.64 & 1.22 \\
\hline \multicolumn{7}{|c|}{$2 \times 3$ bolt-holes } \\
\hline $14-14$ & 14 & 84 & 84 & 4.56 & 3.67 & 1.04 \\
\hline $14-28$ & 14 & 84 & 84 & 7.54 & 6.46 & 1.17 \\
\hline $14-42$ & 14 & 84 & 84 & 7.81 & 8.51 & 0.92 \\
\hline $14-56$ & 14 & 84 & 84 & 9.64 & 10.57 & 0.91 \\
\hline
\end{tabular}

$D_{1}$ : displacement at maximum load from ABAQUS simulation.

$D_{2}$ : displacement at maximum load from calculation.
4.1.1. Plate with more than 2 bolt-holes in the loading direction For plate with more than 2 bolt-holes in the loading direction, the failure conditions are summarized as below:

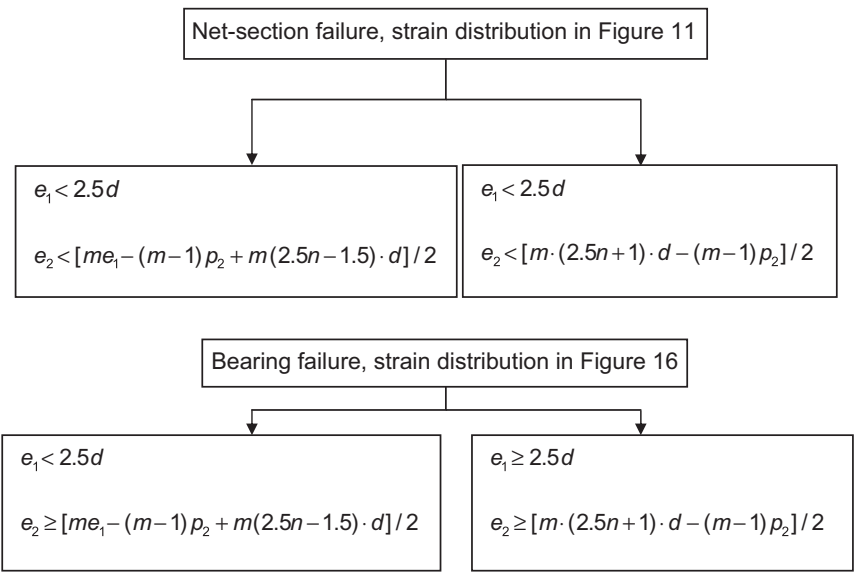

For mixed failure mode (net-section/bearing mixed failure), refer to Fig. 17 for tensile strain calculation.

4.1.2. Plate with 2 bolt-holes in the loading direction

For plate with 2 bolt-holes in the loading direction, the failure condition is summarized as below:

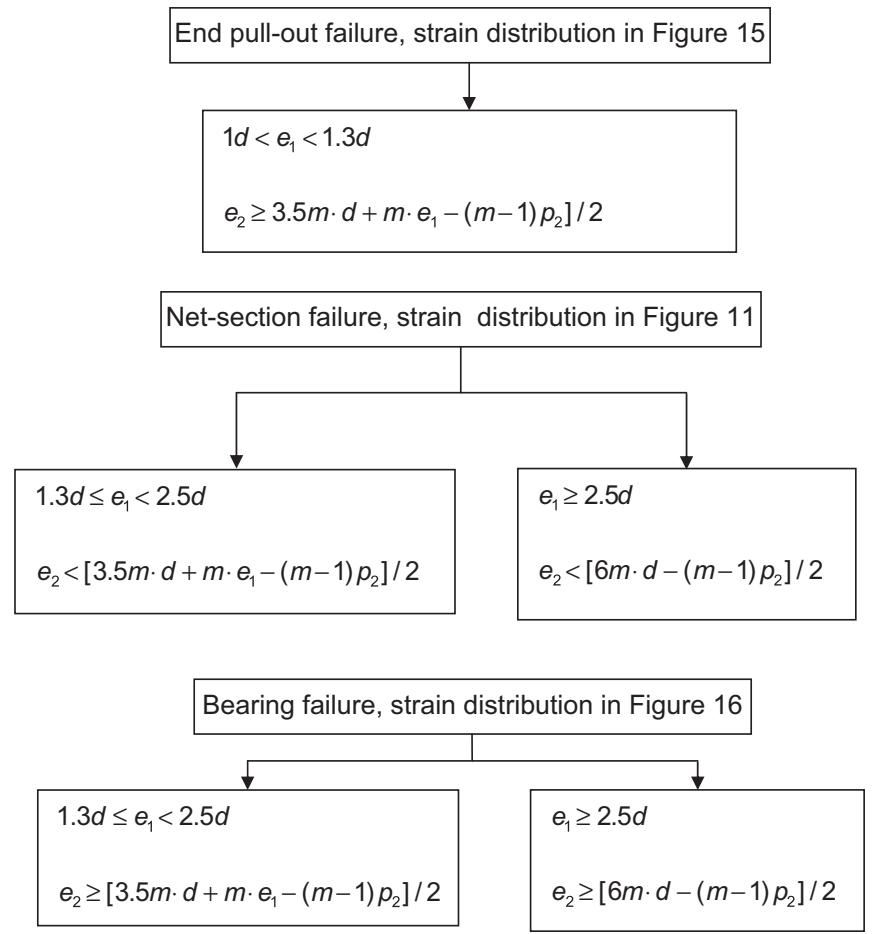

For mixed failure modes (net-section/end pull-out, net-section/ bearing), refer to Fig. 18 for tensile strain calculation.

\subsection{Compressive strain}

1. See Fig. 13 for region of compression strain in front of the bolt hole.

2. Compression strain $=0$ if $e_{2} \leq 0.75 d$. 


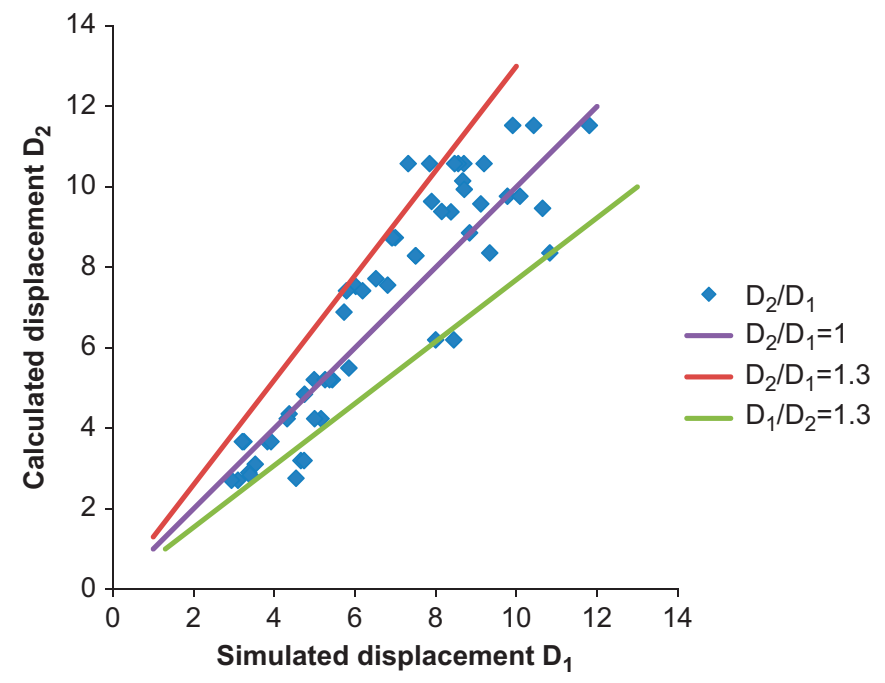

Fig. 19. Simulated displacement vs. calculated maximum plate displacement.

3. Compression strain $=1.0$ if $e_{2} \geq \min \left\{\left[m e_{1}-(m-1) p_{2}+\right.\right.$ $m(2.5 n-1.5) d] / 2,1.75 d\}$.

4. Interpolation between (2) and (3) above.

\subsection{Bolt hole elongation}

Once the tensile and compressive strain distributions are determined, the connection displacement is the sum of the tensile elongation around the 1st set of inner bolts and the compressive pile up in front of the 1 st set of inner bolts. In the special case when end pull-out failure happens in plates with 2 bolt-holes in the loading direction, the compressive displacement of the 1st set of inner bolts should be replaced by the end pull-out displacement of the outer bolts if the latter is smaller.

\section{Conclusions}

This paper has presented a comprehensive numerical and analytical study of the behavior of thin-walled plate with multiple bolts under shear, emphasizing on plate displacement, i.e. the elongation of the 1 st set of inner bolt-holes (furthest away from the plate end). The following conclusions may be drawn:

(1) The general finite element package ABAQUS was an accurate and effective tool in simulating detailed plate behavior.

(2) Eurocode 3 and the Australian/New Zealand standard can be used to predict plate initial stiffness and strength.

(3) The plate displacement is controlled by elongation of the $1 \mathrm{st}$ set of bolt holes. To predict the maximum plate displacement, the tensile strain distribution around the bolt hole may be considered to be linearly distributed between five critical points. Compressive strain also exists in front of the 1st set of inner bolts.

(4) This paper has proposed a method to calculate the strains at these critical points according to three failure modes (net section failure, bearing failure, end pull-out) and transition from one to another. The calculation procedure is summarized in Section 4.

(5) Comparisons between the calculation results and ABAQUS simulation results gave an average difference of $14.3 \%$ and standard deviation of $9.4 \%$. The analytical results are considered accurate.

\section{Appendix A. Calculation example}

End distance: $e_{1}=1 d$, Edge distance: $e_{2}=1 d$, bolt hole diameter $d=14 \mathrm{~mm}$, bolt-hole number $6(m=2, n=3)$, spacing $p_{1}=6 d$, $p_{2}=6 d$ (Fig. 20).

Plate thickness: $1.5 \mathrm{~mm}$, ultimate tensile stress of steel $=320$ $\mathrm{N} / \mathrm{mm}^{2}$, Poisson's ratio $=0.3$, ultimate tensile strain of steel $=0.35$.

1. Calculation of initial stiffness

Using the initial stiffness formula provided by Eurocode 3 to calculate a single bolt row in loading direction

$$
\begin{aligned}
& k_{1}=24 n_{b} k_{b} k_{t} d f_{u} \\
& n=3 \\
& k_{b}=\min [(0.25 \times 1 d / d+0.5),(0.25 \times 6 d / d+0.375), 1.25]=0.75 \\
& k_{t}=\min \left[1.5 \frac{t_{j}}{d_{M 16}}, 2.5\right]=0.14 \\
& k_{1}=24 \times 3 \times 0.75 \times 0.14 \times 12 \times 320=29,030.4
\end{aligned}
$$

There are 2 bolt rows perpendicular to the loading direction, therefore the initial stiffness is

$K=2 k_{1}=2 \times 29,030.4=58,060.8(\mathrm{~N} / \mathrm{mm})$

Abaqus simulation result $=56,201 \mathrm{~N} / \mathrm{mm}$.

2. Calculation of maximum load bearing capacity Since the bolt number is more than 2 in the loading direction, end pull-out failure will not happen.

Net-section failure load is

$$
\begin{aligned}
F_{t} & =A_{n} f_{u}=\left(2 e_{2}+p_{2}-2 d\right) t f_{u}=(2 \times 14+6 \times 14-2 \times 14) 1.5 \\
& \times 320=40.32(\mathrm{KN})
\end{aligned}
$$

Bearing failure load is

$$
\begin{aligned}
F_{b}= & 2 F_{1}+2 F_{2}+2 F_{3}=2 t e_{1} f_{u}+2 \times 2.5 d t f_{u}+2 \times 2.5 d t f_{u} \\
= & 2 \times 1.5 \times 14 \times 320+2 \times 2.5 \times 14 \times 1.5 \times 320 \\
& +2 \times 2.5 \times 14 \times 1.5 \times 320=80.6(\mathrm{KN})
\end{aligned}
$$

$F_{t}<F_{b}$, therefore it is net-section failure. The failure load is $40.32 \mathrm{KN}$.

Abaqus simulation result $=41.48 \mathrm{KN}$.

3. Calculation of displacement at maximum load

For tensile strain, the lower bound of edge distance is $e_{2 l}=1 \mathrm{~d}$. The upper bound of edge distance is $e_{2 u}=(2.5 n-1.5) d+e_{1}$ $-p_{2} / 2=(2.5 \times 3-1.5) d+d-3 d=4 d \quad e_{2}=e_{2 l}$, therefore it is net-section/bearing mixed failure (Fig. 21).

\section{A.1 Tensile strains}

For pure net-section failure mode:

The tensile strains are

$\varepsilon_{A O}=0, \quad \varepsilon_{B O}=0, \quad \varepsilon_{C O}=0.35$

Fig. 22 shows the tensile strain distribution around the bolt hole.

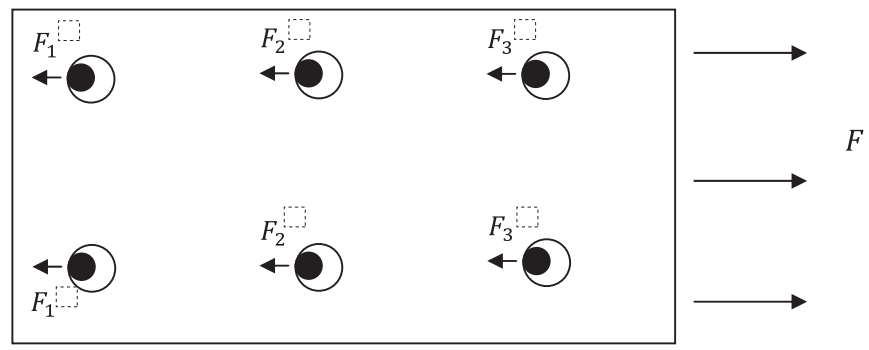

Fig. 20. Plate with 6 bolt-holes. 


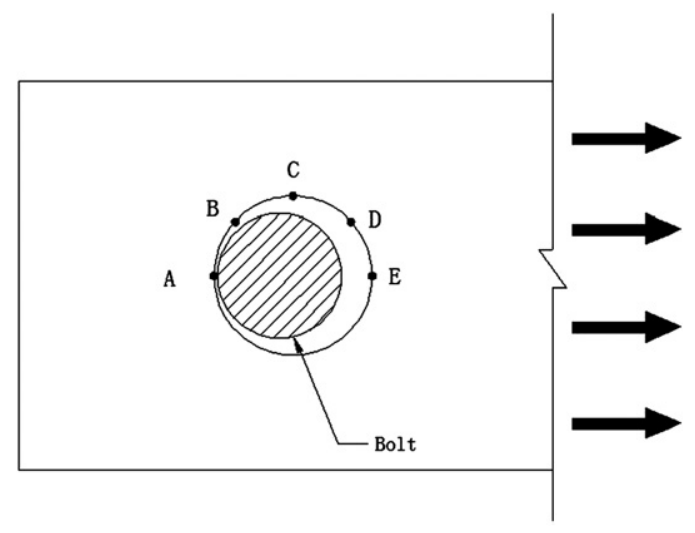

Fig. 21. Critical points on inner bolt-hole.

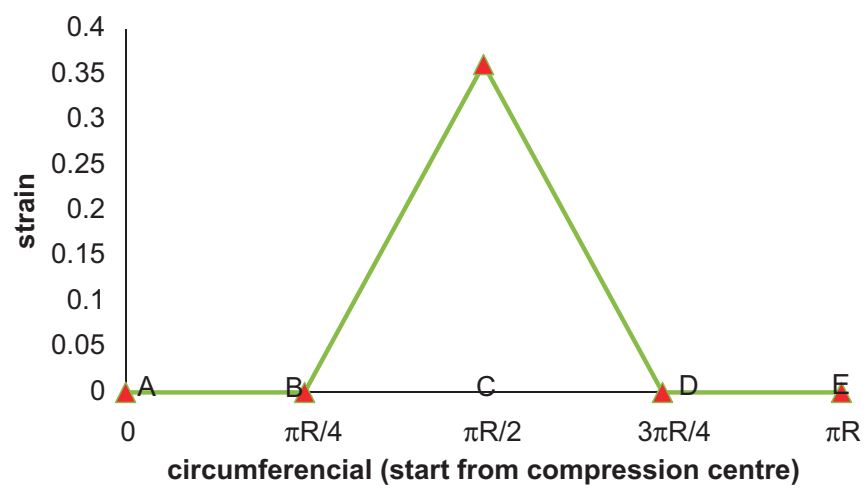

Fig. 22. Tensile strain distribution around bolt hole.

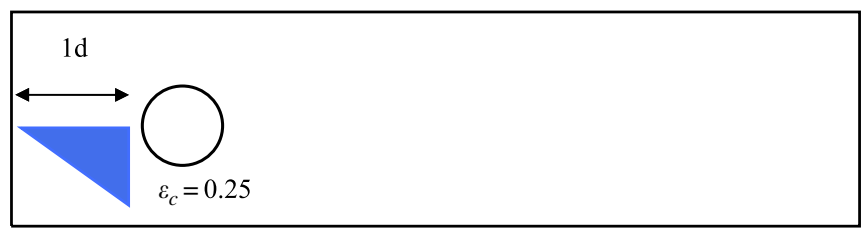

Fig. 23. Compressive strain distribution.

The total bolt-hole elongation due to tensile strain can be calculated as

$D_{T}=\frac{1}{2} \times 2 \frac{\pi R}{4} \varepsilon_{C O}=3.14 \times 7 \div 4 \times 0.35=1.92(\mathrm{~mm})$

\section{A.2 Compressive strain}

For compressive strain, at the lower bound of edge distance $0.75 d$, the compressive strain is 0 . At upper bound of edge distance $e_{2 u}=\min (4 d, 1.75 d)=1.75 d$, the compressive strain is 1.0 .
Since $e_{2 l}<e_{2}<e_{2 u}$, the compression strain is obtained by interpolation

$$
\varepsilon_{C}=\frac{1}{1.75 d-0.75 d} 0.25 d=0.25
$$

Fig. 23 shows the compressive strain distribution along the plate length in front of the bolt.

Therefore, the compressive displacement is

$D_{C}=\frac{1}{2} d \varepsilon_{C}=0.5 \times 14 \times 0.25=1.75(\mathrm{~mm})$

The total displacement of the plate is

$D=D_{T}+D_{C}=1.92+1.75=3.67(\mathrm{~mm})$

Abaqus simulation result $=4.56 \mathrm{~mm}$.

\section{References}

[1] CEN. Eurocode 3. Design of steel structures, part 1.3: general rules, supplementary rules for cold-formed members and sheeting. British Standards Institution; 2006.

[2] Kim TS, Kuwamura H. Finite element modeling of bolted connections in thinwalled stainless steel plates under static shear. Thin-walled Structures 2007;45(4):407-21.

[3] Kim TS, Kuwamura H, Cho TJ. A parametric study on ultimate strength of single shear bolted connections with curling. Thin-walled Structures 2008;46(1):38-53.

[4] Kim TS, et al. Investigation on ultimate strength of thin-walled steel single shear bolted connections with two bolts using finite element analysis. Thinwalled Structures 2009;47(11):1191-202.

[5] Kim T, Jeong H, Cho T. The finite element analysis of the ultimate behavior of thin-walled carbon steel bolted connections. Journal of Constructional Steel Research 2011;67(7):1086-95.

[6] Salih EL, Gardner L, Nethercot DA. Numerical investigation of net section failure in stainless steel bolted connections. Journal of Constructional Steel Research 2010;66(12):1455-66.

[7] Salih EL, Gardner L, Nethercot DA. Bearing failure in stainless steel bolted connections. Engineering Structures 2011;33(2):549-62.

[8] Rogers CA, Hancock GJ. Bolted connection tests of thin G550 and G300 sheet steels; 1997.

[9] Rogers CA, Hancock GJ. Ductile and connection behaviour of thin G550 sheet steels. Thin-walled Structures 1998:145-52.

[10] Rex CO, Easterling WS. Behavior and modeling of a bolt bearing on a single plate. Journal of Structural Engineering_ASCE 2003;129(6):792-800.

[11] Yan S, Young B. Tests of single shear bolted connections of thin sheet steels at elevated temperatures-part I: steady state tests. Thin-walled Structures 2011;49(10):1320-33.

[12] Yan S, Young B. Tests of single shear bolted connections of thin sheet steels at elevated temperatures-part II: transient state tests. Thin-walled Structures 2011;49(10):1334-40.

[13] He YC, Wang YC. Load-deflection behaviour of thin-walled plates with a single bolt in shearing. Thin-walled Structures 2011;49(10):1261-76.

[14] AS/NZS. Cold-formed steel structures-AS/NZS 4600. Sydney, Australia: NSW; 1996.

[15] Hibbitt KS, Sorensen, Inc. ABAQUS/standard user's manual, I-III, version 6.3. Hibbit, Karlsson and Sorenson, Inc.; 2001.

[16] CEN. BS EN 1993-1-8, Eurocode 3: design of steel structures, part 1.8: design of joints. British Standards Institution; 2005.

[17] American Iron and Steel Institute. 1996 Edition of the specification for the design of cold-formed steel structural members. Washington, DC; 1997. 